\title{
Baum- und Waldbilder aus der Schweiz
}

Erste Serie

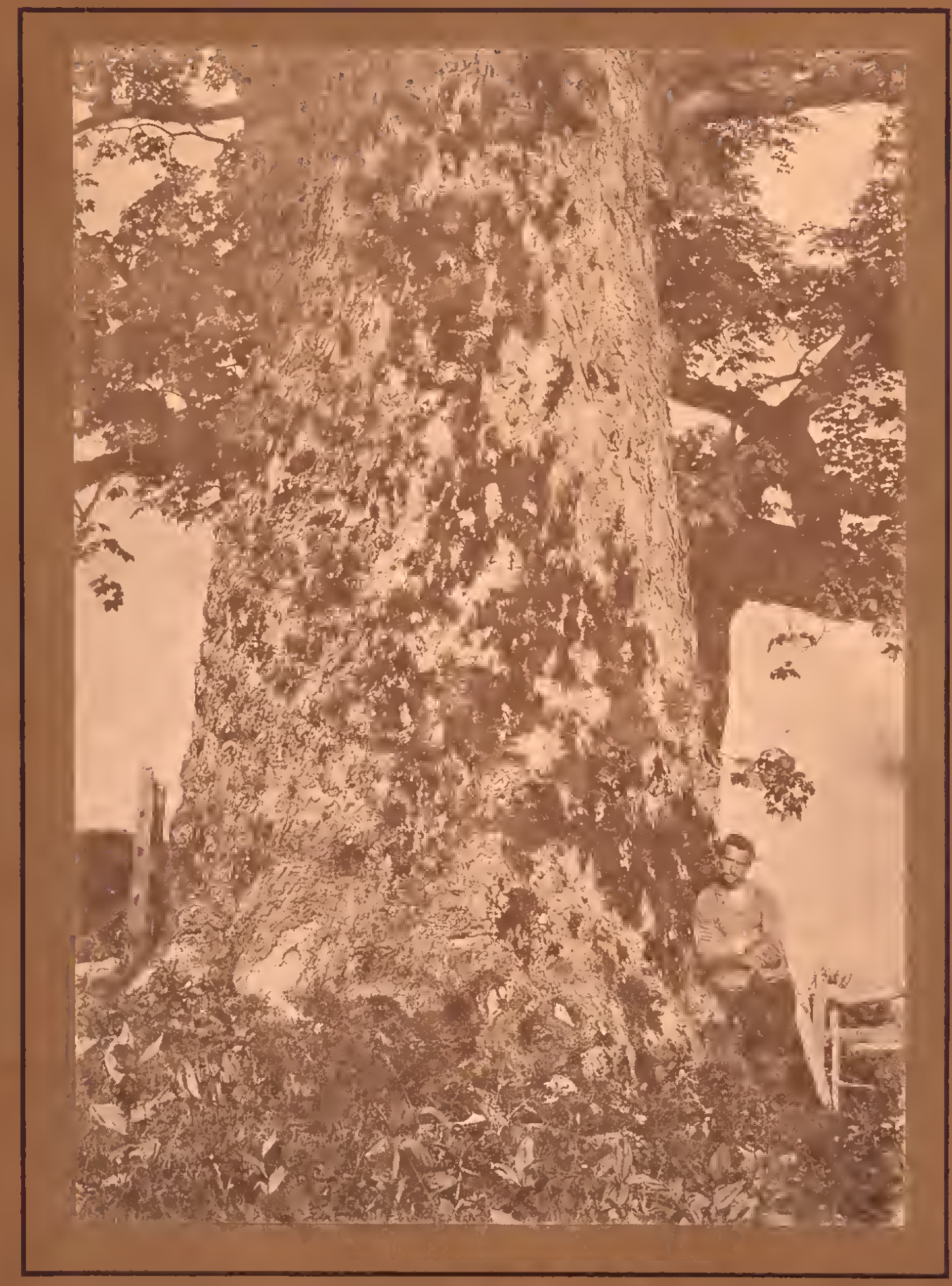

Herausgegeben vom

Schweizerischen Departement des Innern

BERN - VERLAG VON A. FRANCKE - 1908 


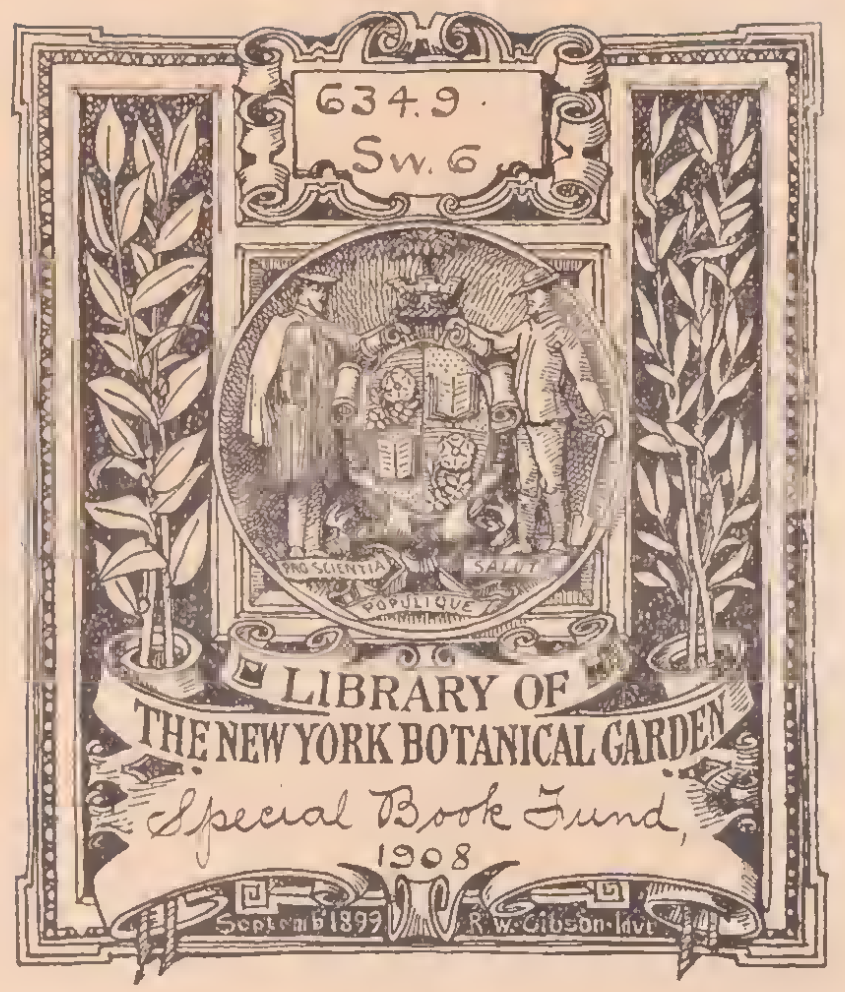




\title{
Baum- und Waldbilder aus der Schweiz
}

\author{
Erste Serie
}

Herausgegebcu vom

S.nchweizerischen Departement des Innern

Abteilung Forstwesen

(Oberforstinspektorat)

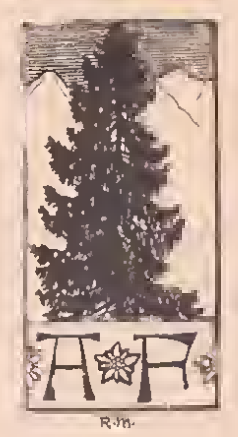





\section{VORWORT.}

Seit dem Erscheinen der Schlusshieferung des Baumalbums der Schweiz, 1900, sind sieben Jahre dahingegangen. Unterdessen haben nicht nur durch Schönheit, Grösse und Geschichte hervorragende Bäume, sondern auch andere Naturgegenstände besondere Beachtung gefunden, und hat sich eine schweizerische Naturschutzkommission mit zahlreichen kantonalen Sektionen gebildet zum Schutz und zur Bekanntmachung derselben. Es dürfte daher die Zeit gekommen sein, im Sinne der Bestrebungen dieser Kommission, das Baumalbum fortzusetzen. Dass dies nicht früher geschehen, lag daran, dass das eidgen. Oberforstinspektorat durch andere Arbeiten dringender Natur stark in Anspruch genommen war, auch zog sich der Entscheid über die Frage, ob an der bisherigen Grösse der Bilder von $30: 40 \mathrm{~cm}$ festgehalten, oder ein kleineres Format gewählt werden solle, sehr in die Länge. Die veröffentlichten Bilder haben zwar allgemein Anklang gefunden, sie lassen die Schönheit und den Charakter des Baumes unzweifelhaft kräftiger hervortreten und besser zur Geltung kommen, als kleinere, das Werk wird aber durch die Grösse der Bilder etwas unhandlich und trotz des verhältnismässig niedrigen Preises doch nicht billig genug, um beim grossen Publikum die gewünschte Verbreitung zu finden. Und doch wollte man gerade diesem die Baumbilder vor Augen führen und dasselbe dadurch zum Genuss an Naturschönheiten heranziehen. Das eidgen. Departement des lnnern hat sich daher entschlossen, künftighin die Baumbilder in der Grösse von 15 auf $21,5 \mathrm{~cm}$ erscheinen zu lassen. Jede Lieferung wurde auf zwanzig Bilder festgesetzt, wovon einige im schweizerischen Baumalbum im Grossformat bereits enthalten sind.

Die Bilder sollen ausnahmsios den ganzen Baum umfassen. Um einzelne interessante Teile desselben besser hervorzuheben, werden diese in vergrössertem Masstabe in den Text aufgenommen. Darstellungen von Verunstaltungen von Bäumen, durch Krankheit, Schneedruck, Wind, Tiere usw., sind ausgeschlossen, denn das Werk soll nur im Dienste der Kunst stehen, beim Volk den Sinn für Naturschönheiten wecken und zur Ausbildung desselben beitragen, und dies insbesondere auch durch Vermittlung der Schulen. Zugleich soll es den Naturschutz unterstützen.

Ausser einzelnen, freistehenden Bäumen finden auch Baumgruppen und Bestandesbilder Aufnahme, um die Vereinigung von Bäumen zu einem schönen Ganzen zur Darstellung zu bringen und auf dieselben aufmerksam $z$ u machen. Es wird damit auch das Forstfach die ihm gebührende Berücksichtigung finden. Bei einigen Holzarten zeichnet sich das innere Gerüst des Kronenwerkes im unbelaubten, winterlichen Zustande durch Schönheit und Eigentümlichkeit der Gestaltung aus, so bei Eichen und Birken. Einige Weidenarten blühen in diesem unbelaubten Zustande, vor dem Blattrieb. Auf das botanische Gebiet begeben wir uns nicht weiter, als es eine kurze Beschreibung des Baumes verlangt, und ebenso wird die Örtlichkeit des Baumes nur insoweit angegeben, als es erforderlich erscheint, um denselben leicht aufzufinden. Dagegen wird der Standort, in dem der Baum aufgewachsen, sowie dessen nächste Umgebung und Geschichte, wo eine solche zu ermitteln ist, genau beschrieben werden und 
ebenso die Gestaltung des Baumes samt Angaben über Stanmumfang, Kronendurchmesser, Höhe usw.

Auf die Verbreitung der Holzart, welcher der Baum angehört, treten wir deshalb nicht ein, weil uns dies zu weit führen würde, und auch nicht notwendig erscheint, da wir im Werk von Dr. Christ, „Das Pflanzenleben der Schweiz", hierüber eine klassische Arbeit besitzen, ferner eine Menge Lokalfloren und Monographien von schweiz. Holzarten bereits erschienen sind und für nächste Zeit in Aussicht stehen; ferner ist in Auftrage des eidgen. Departements des lnnern das grossangelegte Werk, „Erhcbungen über die Verbreitung der wildwachsenden Holzarten in der Schweiz", im Erscheinen begriffen.

In kleinem Format haben bereits der schweizerische Forstverein in seinen Organen, "Schweizer. Zeitschrift für Forstwesen“, das „Journal forestier Suisse“ und andere Veröffentlichungen botanischen oder forstlichen lnhalts Bilder von Bäumen und Baumgruppen der Schweiz gebracht, auch ist hier noch das Werk "Charakterbilder mitteleuropäischer Waldbäume 1", von Prof. Dr. L. Klein, zu nennen.

Andere Staaten sind mit dem Schutz und der Bekanntmachung von Bäumen und anderen interessanten Naturgegenständen, sogen. Näturdenkmälern, ebenfalls vorgegangen. Preussen hat sogar für Ermittlung, Erforschung und Erhaltung von Naturdenkmälern eine besondere Beamtung geschaffen, nachdem Prof. Dr. Conwentz sein forstliches Merkbuch veröifentlicht und Verschiedenes hierüber geschrieben. Schlieckmann hat die bemerkenswerten Bäume Westfalens behandelt, und Fr. Stützer uns mit den grössern ältesten und sonst merkwürdigen Bäumen Bayerns, Prof. Dr. Klein mit denjenigen des Grossherzogtums Baden bekannt gemacht.

Schliesslich sei noch bemerkt, dass das eidgen. Oberforstinspektorat die Aufnahmen von schönen Bäumen der Schweiz im ursprünglichen Format von $30: 40 \mathrm{~cm}$ der Veröffentlichung der kleinen Bilder wegen nicht aufgegeben hat, sondern damit für seine Sammlung von Photographien und zu besonderen Bestimmungen fortfahren wird.

Dr. J. Coaz. 


\section{Beschreibung der Bäume.}

\section{$\infty$ \\ Tafel I. Die Linde von Freiburg.}

(Tilia platyphyllus Scop.)

Wir finden in der Schweiz wohl wenige Bäıme, die würdiger wären, an die Spitze unseres Albums gestellt zu werden, als die Linde von Freiburg. Seit bald $4 \frac{1}{2}$ Jahrhunderten hat das Leben und Treiben der Stadt und der Republik Freiburg sich um sie bewegt, Generationen sind ilırem Sprossen von Blättern und Blüten, der Fruchtbildung und dem Blattfall Jahr um Jahr gefolgt. Die Linde ist die älteste und ehrwürdigste Bürgerin von Stadt und Land und mit deren Geschichte innigst verwachsen; ihr Anblick erfreut das Herz eines jeden Freiburgers. Als bei der Erweiterung der Rue des Alpes die Entfernung der Linde zur Sprache kam, waren die Bürger darob aufs höchste entrüstet, der Baım blieb stehen und die Strasse musste sich bequemen, beidseitig sich um denselben herumzubiegen. Und er wird seinen Platz behaupten, solange der morsche Stamm seine Krone noch zu tragen vermag oder bis ein Sturm oder starker Schneefall die Freiburger in Trauer versetzen wird.

Der heute (bei $1.3 \mathrm{~m}$ über Boden) $4.7 \mathrm{~m}$ in Umfang messende Stamm ist hohl, eine nur dünne Rinden- und Splintschicht trägt den schweren Baumkörper, der von einer nach oben sich erweiternden, klaffenden Spalte durchzogen ist. Ein Drahtgitter schützt das Innere des Stanmes vor Beschädigungen. An ihrer Aussenseite ist die Rinde stark aufgerissen und der Wurzelstock mit zahlreichen Wülsten bedeckt. Bei $1.90 \mathrm{~m}$ (über Boden) geht ein starker, knorriger Ast und bei $2.80 \mathrm{~m}$ ein zweiter voin Stamme ab. Der erstere misst im Umfang $2.22 \mathrm{~m}$, der andere $1.90 \mathrm{~m}$. Auch diese Äste sind ausgefault, aber gegen Verbreitung der Fäulnis und zur Verstärkung ihrer Tragkraft mit Zement ausgefüllt. Schon vor Jahren wurden sie von Stürmen gebrochen und auch künstlich gestutzt, damit sie kräftiger wieder ausschlagen. Die jüngern untern Triebe sind hängend, so dass der Kronenmantel bis nahe zum Boden heruuterfällt.

Bei diesem gebrechlichen Astbau bedurfte die Linde seit vielen Jahren schon einer Stütze, wozu, wie beistehendes Bild zeigt, vier steinerne Pfeiler mit vier Querbalken dienen, welchen die alten Äste aufliegen, die überdies noch durch Eisenstangen zusammengehalten werden. An einem der Pfeiler ist ein vergitterter Kasten angebracht, der amtliche Bekanntmachungen enthält.

Das Textbild bietet einen Blick in das Innere der Baumkrone, das Einzelbild zeigt das Äussere derselben, jedoch nicht in der Normalform einer Kuppel, denn infolge des Alters und der Beschädigungen ist der Habitus unregelmässiger und gedrückter, kugelförmiger geworden. Der grösste Durchmesser der Krone beträgt nur $15.5 \mathrm{~m}$, die Baumhöhe nur $13.3 \mathrm{~m}$.

Bei einem Besuche der Linde am 7. Juli 1906 war ihre Belaubung frisch dunkelgrün und reich von herrlich duftenden Blüten durchwirkt. 
Aus der Krone ragt eine Latte empor, die bei öffentlich-festlichen Anlässen, an welchen die Linde sich bcgreiflicherweise auch beteiligt, als Fahnenstange dient. Um den Stamm herum und daneben sind schon von Alters her Bänke angebracht, auf welchen die Freiburger, besonders an Markttagen, gerne ausruhen und sich unterhaltell.

Die Linde Freiburgs nimmt eine zentrierte, vornehme Lage auf dem Platze des Stadtrathauses und des Regierungsgebäudes ein. Von ihr gehen vier Strassen aus, nämlich die Rue de la grande fontaine gegen das Stadtquartier Neuveville hinunter, die neue, aussichtsreiche Alpenstrasse, die Lausanner- und die Lindenstrasse.

Über die Geschichte und das Alter der Linde hat uns Herr Jos. Schneuwly, Staatsarchivar des Kantons Freiburg, nach sehr gründlichem Studium, eine einlässliche, verdienstvolle Arbeit (in französischer Sprache) zur Vcrfügung gestellt, für welche wir ihm hiermit unsern besten Dank aussprechen. Wir lassen nun diese Arbeit in der Übersetzung ins Deutsche folgen:

Wenn man die Chronisten, die Überlieferung und die Legenden bezüglich der Pflanzung der Freiburger Linde zu Rate zieht, gelangt man zu sehr verschiedenen Ergebnissen. Die Historiker selbst sind hierüber unter sich nicht einig.

Nach den einen würde sich die Linde von der Gründung der Stadt her datieren und hätte somit ein Alter von 700 Jahren. Diese Ansicht muss aber anfgegeben werden, denı man weiss aus sicherer Quelle, dass ein tiefer Graben von der Grabenzalle bis Court Chemin dic Stadt gegen Norden und Osten abschloss. Nach dieser Hypothese hätte die Linde über einem Abgrund oder an den Abhängen eines solchen angepflanzt sein müssen.

Nach der Chronik, welche kürzlich Truyo oder Gurnel zugeschrieben wurde und, nach den Arbeiten des Dr. Büchi, Radellaz zur Ehre gereicht, ferner nach der Freiburger Chronik von 1687, übersetzt und veröffentlicht 1852 durch Heliodore Ræmi, würde die Linde 1470 gepflanzt worden sein. Dieses Datum wurde von Dr. Berchthold, Oberst Perrier, lsedor Ræmi und vom Historiker Ochsenbein angeführt, jedoch mit dem Beifügen, dass die hiervon abweichenden Volksüberlieferungen zu schonen seien.

Und in der Tat hat die Annahme des Datums, welches der Schlacht bci Murten folgt, sehr viel Anziehendes für sich. Es ist dasjenige des 23. Juni 1476, welches auch schon Prof. Michaud in seinen deutschen, zu Ehren der Linde gedichteten Versen angenommen hat und welchem die meisten Schriftsteller gefolgt sind.

Endlich bringt Kneulin, der in seinen diesfälligen Annahınen schwankend war, in den Gemälden der Schweiz (1874), ohne Begründung, das Datum von 1480.

Die nachstehende Erzählung Herzogs in seinen Schweizersagen (1887) stützt sich auf das Datum der Murtner-Schlacht:

„Sofort, nachdem die Eidgenossen Karl den Kühnen bei Murten aufs Haupt geschlagen hatten, entsandte der Hauptmann der Freiburger einen Jüngling mit dem Auftrage, in eilendem Laufe der besorgten Vaterstadt die freudige Siegesbotschaft zu überbringen. Der Jüngling hatte soeben in frohem Siegesgefühl seinen Hut mit einem grünen Lindenzweig geschmückt. Folgsam eilte er, in seine warme Uniform gekleidet, in der Glut der heissen Junisonne gestreckten Laufes nach Freiburg, welche Stadt drei Stunden von Murten entfernt ist. Als or daselbst atemlos auf dem Rathausplatz ankam, steckte er seinen Spiess in die Erde, lehnte sich daran und rief: „Sieg! Sieg!" Dann sank er zusammen und war tot. Man nahm den welken Lindenzweig vom Hut des Jünglings und grub ihn da, wo er seine Augen schloss, in die Erde. Und das Reis gedieh und wurde zu der gewaltigen Linde, deren morscher Stamm noch heute auf dem Rathausplatze steht."

Über einzelnes dieser ergreifenden Erzählung haben wir etwelche Bedenken zu erhebenl. Zunächst fragen wir uns, ob die in Murten Kämpfenden Uniformen getragen. Sodann bemerken wir, dass das Rathaus damals noch nicht da gestanden, wo wir es heute sehen, es befand sich in der Metzgergasse, an Stelle dẹ heutigen Postfiliale. 


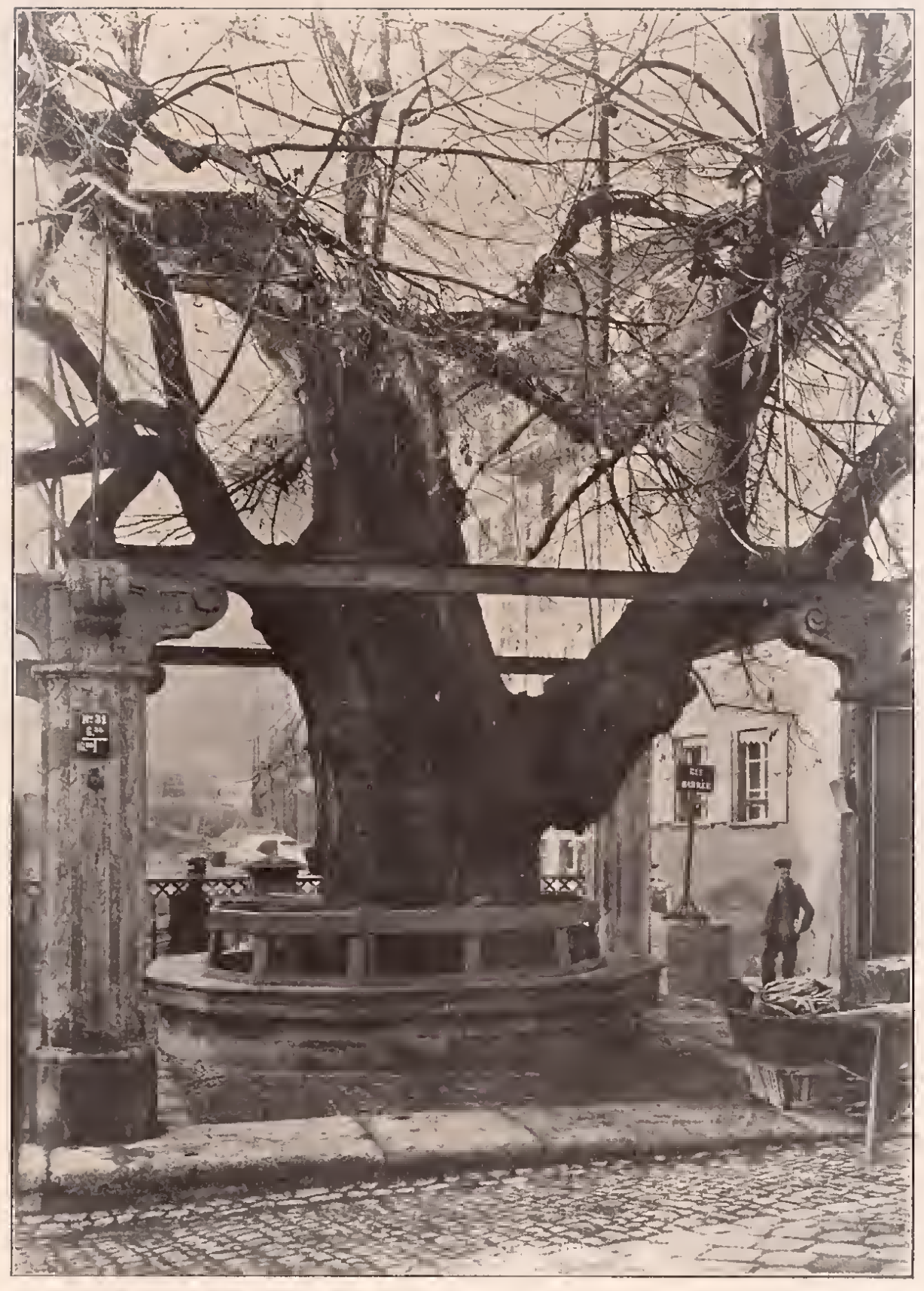

Die Linde in Freiburg. 
Endlich finden wir in der Rechnung des Schatzmeisters von 1476, dass den beiden Läufern, welche die Siegesbotschaft brachten, eine Entschädigung gegeben wurde. Es waren dies Johann Stoss und Heinrich, die Diener des Seigneurs de Cugy. Da die Läufer Entschädigungen empfangen haben, sind sie nicht gleich nach Ankunft von Murten her tot niedergefallen.

Vergessen wir hier nicht zu bemerken, dass obige Annahme des Datums der Schlacht von Murten allgemeinen Anklang gefunden hat und dass unsere deutschen Landleute die Linde von Freiburg immer noch mit "Murtner-Linde" bezeichnen.

So verführerisch auch die Volksüberlieferung ist, welche dem Datum von 1476 Annahme verschafft hat, so erachten wir unserseits doch, dass man sich auf das Datum von $1470 \mathrm{zu}$ vereinigen habe. Hier unsere Gründe:

"Zu oberst in der Grande rue, da wo gegenwärtig das Rathaus und das Regierungsgebäude stehen, erhob sich bis 1463 ein Turm; man nannte ihn: "la tour du Bourg" oder "la tour d'Autriche". Möglich, dass es ein altes Schloss der Herzoge von Zähringen war. 1463 wurde der Turm geschleift. Der Graben, von dem wir oben gesprochen, wurde mit einem Gewölbe überbaut und dieses mit einer Erdschicht überdeckt. Daraus entstund später die Strasse Pont muré. Dank dieser Umgestaltung kamen zwei neue Plätze und die Vergrösserung des Platzes Notre Dame zustande. Auf einem der Plätze errichtete man den Brunnen Saint Georges und den Kornmarkt - es ist dies die Stelle des heutigen Rathauses - auf dem zweiten pflanzte man früher oder später die Linde, und auf den dritten kam der Brunnen Samson zu stehen. Alle diese Werke wurden zwischen 1463 und 1467 oder 1470 ausgeführt, denn in diesen Jahren wurde der nahe Platz des Petit Paradis gepflastert.

Die erste Erwähnung der Linde in authentischen Dokumenten findet sich in der Rechnung des Schatzmeisters des ersten Semesters des Jahres 1482. Es steht dort, dass man den Bauern der Herrschaft von lllens, welche 14 Wagen Tuff in die Stadt geführt, um den Sitz, d. h. die plate forme des Baumes vor dem Spital zu erstellen, 6 livres, 8 sols et 4 deniers bezahlt habe. Es kamen weiter noch 28 Taglöhne für Maurer und Gehülfen in Rechnung.

In der Rechnung des Schatzmeisters für das zweite Semester 1490 finden wir noch angeführt, dass der Tischler Bernard eine Bank unter der Linde vor dem Spital erstellt liabe.

Im Jahre 1519 (oder 1520) wurde ein Arbeiter beauftragt, erwähnte Bank mit einem Dache zu versehen.

Die Chronik Rudellaz (1560) berichtet, dass die Linde vor dem Spital und ob dem alten Stadtgraben 1470 gesetzt wurde und gut gedieh, im Jahre 1550 eine Abastung erlitt, (und erst by unseren Zyten 1560 gestumpelt) infolge welcher sie noch stärker trieb denn früher und sich gänzlich verjüngte (schöner dann vor ussgeschossen und ernüwert).

Der älteste, von 1584 datierte Plan der Stadt Freiburg stellt uns die Linde gestützt auf einen hölzernen Rahmen im Quadrat dar, der auf vier ebenfalls hölzernen Säulen ruht. lch vermute, Jass diese Rahmen und diese Säulen 1560 erstellt wurden.

Um während des Marktes zwischen den Käufern und Verkäufern sich erhobene Streitigkeiten zu behandeln, hatte man ein besonderes Gericht eingeführt, das anhängig gemachte Fälle unter der Linde aburteilte. Dieses Gericht wurde deshalb das "Lindengericht" genannt. Den 7. Juli 1578 wurde es abgeschafft, den 10. Juli 1581 wieder eingeführt und dann neuerdings aufgehoben. Nochmals hergestellt, wurde es wieder aufgelöst (weil es eine Art Ergötzlichkeit war).

Im Jahre 1668 war es üblich, unter der Linde Anzeigen anzuschlagen. Der Verfasser der Chronik von 1687 berichtet: "Unter der Linde kommen wegen der Lage und Lieblichkeit des Ortes die ersten Seigneurs der Stadt zusammen. Sie lieben es, in dem wohltätigen Schatten dieses hochgewachsenen Baumes sich niederzulassen, der seine Äste allseitig weit ausbreitet und ringsum ein abgerundetes Gewölbe bildet, und dessen Blüten, wenn sie aus dem grünen Laube hervortreten, die Luft mit ihrem herrlichen Duft erfüllen. Es ist hier am Ort zu sagen, 
dass er 1470 gepflanzt wurde und folglich gegenwärtig (1687) ein Alter von 217 Jahren hat."

Die Säulen aus Solothurner Stein, welchen das Gerüst aufliegt und die hölzernen ersetzen, tragen die Jahreszahl 1756.

Man findet in der Tat in der Rechnung $15 a$ des François Ignace Pettolaz, Edil der Stadt Freiburg, für das Jahr 1756, dass man dem Architekten Nadils Gutscheine für 140 Taler, d. i. 700 livres, für die vier Säulen der Linde gemäss Vertrag ausgestellt hat, wovon 300 livres durch den Bauherrn und 400 durch den Schatzmeister ausgerichtet wurden.

Den 23. Juni 1776 feierte der Dichter Michaud in deutscher Sprache den dreihundertsten Jahrestag der Pflanzung der Linde.

Wenn ein Verbrecher, über den das Todesurteil ausgesprochen worden war, zum Richtplatz geführt wurde, so war es vor der Linde, wo über ihn der verhängnisvolle Stab gebrochen wurde.

1795 welkte das Laub der Linde unter der Hitze eines sehr trockenen Sommers zusehends. Unglücklicherweise fielen einige Raketen, die unvorsichtige Schüler hatten steigen lassen, auf die Linde nieder, die sofort Feuer fing. Alles lief herbei und die Feuerspritzen übergossen den Baum mit einer solchen Wassermasse, dass er — wunderbarlich - im darauffolgenden Frühling mit erneuerter Kraft ausschlug. (F. Perrier, colonel, souvenir de Fribourg.)

1810 gibt der Gemeinderat von Freiburg Fr. 44 für Anstrich der grossen Linde aus (soll wohl heissen des Gerüstes und der Bänke) und Fr. 30 für andere Arbeiten.

Den 26. September 1828 ladet der Gemeinderat das Bauamt, da sich die Rinde der grossen Linde an verschiedenen Stellen vom Stamme abgelöst hatte, ein, anzuordnen, dass dieser den Freiburgern durch das Andenken, das sich an denselben knüpft, und dessen hohen ehrwürdigen Alters wegen so werte Baum, so lange als immer möglich erhalten bleibe und dem natürlichen Eingehen desselben durch Kunst möglichst begegnet werde.

Den 30. März 1838 verbietet der Gemeinderat den Milchhändlern der Stadt, ihre Esel an die Linde anzubinden.

In Nr. 58 des "Narrateur fribourgeois" vom 20. Juli 1841 wird berichtet, dass vorgestern, Sonntag den 18., ein ausserordentlich starker Wind fast den ganzen Tag hindurch geherrscht und eine grosse Anzahl Stämme entwurzelt, Kamine herabgeworfen und Dächer abgetragen habe. Unsere Linde, Zeugin so vieler erhabener und komischer Szenen, wurde nicht verschont. Der königliche Baum verlor seine Krone, gerade 365 Jahre, nachdem man ihn von Murten her erhalten hatte. Bei dieser Gelegenheit haben wir die hohe Achtung des Volkes vor diesem glorreichen Baum bewundert; die anwesenden Bürger hoben jeden Zweig und jedes Blatt sorgfältig auf und schmückten damit ihre Hüte.

Hier folgen die ersten Verse aus dem Gedicht unserers Dichters Louis Bornet über diesen Sturn und dessen Beschädigung der Linde (Narrateur fribourgeois de 1841, Nr. 51 et Emulation de 1852, page 319):

J'ai vue le front sacré de l'arbre qu'on vénère

Dans la poussière humilié!

Le plus brillant rameau du Tilleul centenaire

Sous le coup du vent a crié,

Rapit il tournoyait, dans un poudreux nuage

Poussé par tout les aquilions;

La main de la tempête, arrachant son feuillage

Ah! pourquoi voyons nous ce fils d'une victoire Faible, longuement dessérés;

Lui qui pouvait jadis, s'élançant de la terre

Dans ces bras longs et tortueux,

Etendre avec orgueil une ombre salutaire

Sur la tête de nos ayeux.

Le livrait aux noirs tourbillons.

Der Gemeinderat ordnete den 31. Juli 1844 die Reparatur und den Anstrich des Gerüstes an, welches die Äste der Linde unterstützt. 
Den 13. April 1852 beauftragte der Gemeinderat das Bauamt in Anbetracht, dass die grosse Linde einzugehen drohe und man sie nicht länger vernachlässigen dürfe, nachzusehen, was zur Erhaltung des Baumes und Herstellung eines angemessenen Äussern zu tun sei.

1869 waren die Querbalken, welche auf den Säulen ruhen, angefault; sie wurden ausgewechselt, eine Arbeit, die Fr. 200 kostete.

Den 5. August 1874 wurde dem Gemeinderat angezeigt, der Wurm habe die Äste angegriffen, worunter die Belaubung leide. Der Rat erteilte Befehl, dass dagegen Massnahmen ergriffen werden.

(Aus dem französischen Originaltext ins Deutsche übersetzt von Dr. J. Coaz).

\section{Tafel II. Die Ulme von Bissone, Kt. Tessin.}

(Ulmus campestris L.)

Wenn man sich von Melide über den Brückendamm (Ponte Diga), der den Luganersee durchquert, nach dem gegenüberliegenden Bissone begibt, so sieht man auf dem gegen den See offenen Platz dieser Ortschaft einen Riesenbaum weit über alle Gebäude und über die umstehenden Bäume emporragen. Es ist unsere Ulme, die der Geschichte von Bissone angehört. Gegen 1500 wurden nämlich auf erwähntem Platze vier Ulmen gepflanzt, von welchen eine vor etwa 87 Jahren abgestorben und die zweite vor 25 Jahren vom Blitze zertrümmert wurde. Ein Ast dieser letztern hatte eine Länge von $17 \mathrm{~m}$ und galt als Brennholz Fr. 60. Von einem dritten, nicht mehr vorhandenen Baum nimmt man an, er sei bald nach seiner Verpflanzung eingegangen.

Die allein den Platz noch beherrschende Ulme ist in einem Landschaftsbilde der Kirche St. Rochus in Bissone von 1630 dargestellt. Nach obigen geschichtlichen Angaben können wir das Alter der Ulme mit ziemlicher Sicherheit auf etwas über 400 Jahre annehmen.

Der Baum steht in angeschwemmtem Boden, ungefähr $2 \mathrm{~m}$ über der Seefläche und $276 \mathrm{~m}$ über Meer. Von ihm aus öffnet sich gegen Westen eine freie Aussicht über den Ceresio hinüber nach dem jenseitigen Gestade von Melide, hinauf nach der Ortschaft Carona, dem Monte Arbostoro und St. Giorgio. Gegen den rauhen Nordost- und Ostwind ist der Baum durch die Gebäude von Bissone und die mit Wein und Niederwald bekleidete Gebirgswand zwischen Arogno und Rovio geschützt.

Auf dem Platz um die Ulme hat sich während seines langen Daseins ein mannigfaltiges Volksleben abgespielt, von welchem die Fischer, deren zahlreiche Netze am Seeufer zum Trocknen aufgehängt sind, die Hauptrollen besetzen. Ihnen wird die Ulme (l'olmo) oft, namentlich bei stürmischem Wetter, als willkommenes Signal zur Erreichung des heimatlichen Strandes gedient haben.

Der Stamm misst bei $1.2 \mathrm{~m}$ (über Boden) im Umfang $5.50 \mathrm{~m}$, bei $1.8 \mathrm{~m}$ noch $5.30 \mathrm{~m}$. Er hat eine Höhe von $27 \mathrm{~m}$.

\section{Tafel III. Der Bergahorn im Melchtal.}

(Acer Pseudoplatanus L.)

Obwohl unter dem Laubdach des Melchtaler Ahorn kein Freiheitsbündnis beschworen wurde wie unter demjenigen des Trunser Ahorns, und nichts über dessen Geschichte bekannt ist, so darf doch angenommen werden, dass er zur Zeit der Gründung der schweizerischenl Eidgenossenschaft schon dagestanden, oder dass er doch in die ersten Zeiten der jungen Freiheit 


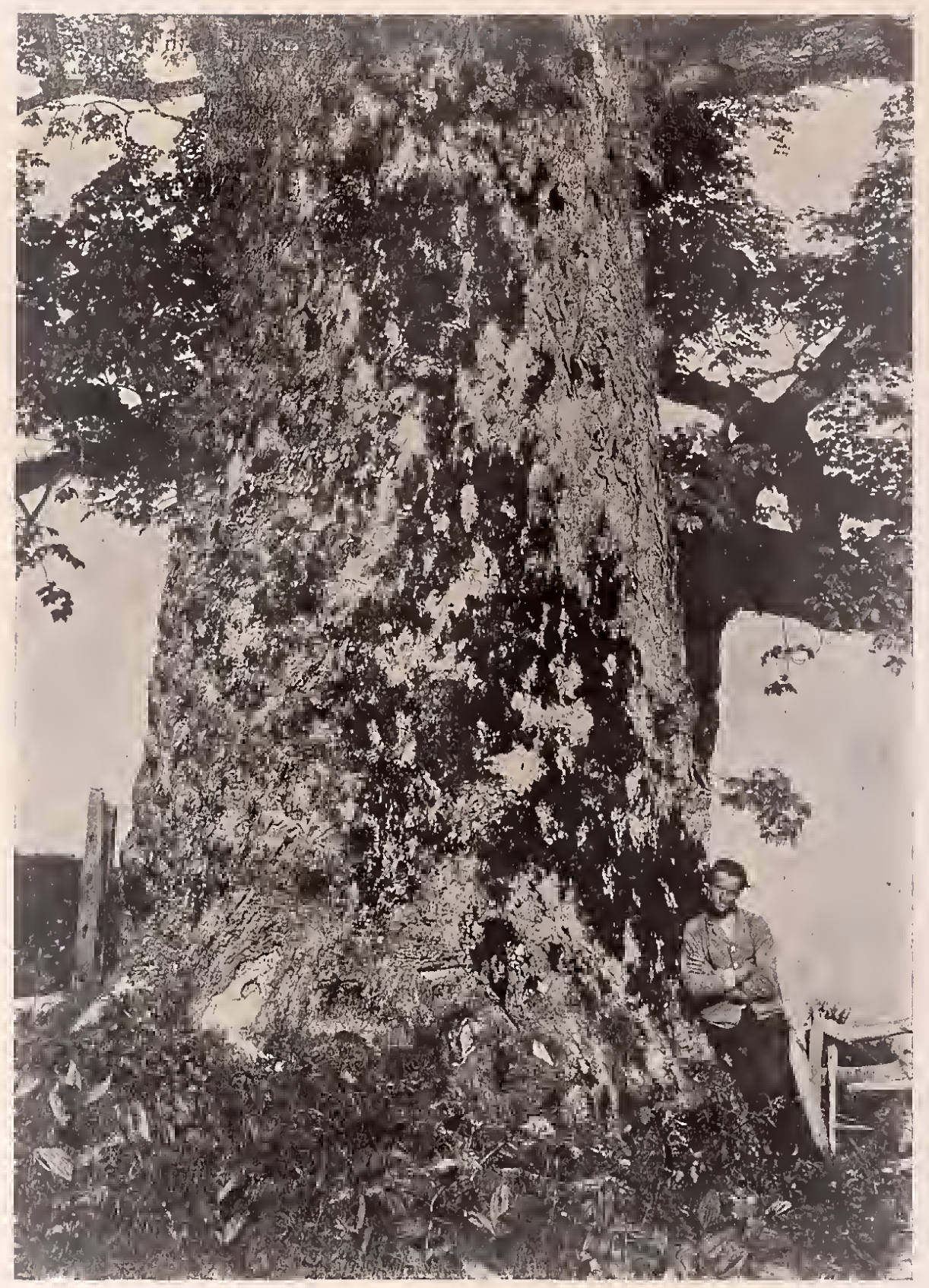

Der Bergahorn im Melchtal. 
hineingewachsen. Er thront 1350 in über Meer, weit hinten, an westlichen Abhang genannten Tales, an der Grenze der beiden Alpen Schwendholz und Ohr, auf Gebiet der Gemeinde Kerns, Kanton Unterwalden o. d. W. Die Ümzäunung, die Scheide zwischen beiden Alpen, lehnt sich, wohl schon seit Jahrhunderten, an den alten Stamm an, und ein kleines Pförtchen führt die Älpler hart an ihm vorüber. Eine Hängefichte steht ihm rechts zur Seite.

Der Baum zieht den Blick schon von weitem auf sich und hält ihn gefesselt durch den kolossalen Stamm und durch den gewaltigen Bau seiner Krone. Zahlreiche abgestorbene Äste und Zweige lassen auf das hohe Alter des Baumes schliessen und zeigen dessen allmähliges Eingehen an.

Das Grundgebirge, auf dem der Ahorn fusst, ist Schrattenkalk. Infolge einer kleinen Bodenabrutschung hat sich eine anläge Terrasse gebildet, wo der Ahorn seinerzeit angeflogen und einen ziemlich tiefgründigen Lehmboden vorgefunden, der ihm zusagt.

Legt man das Messband, bergwärts des Stammes, nahe dem Boden an und misst in horizontaler Richtung den Umfang desselben über die knorrigen Wülste hinweg, so erhält man $12.2 \mathrm{~m}$. In einer Höhe von $70 \mathrm{~cm}$ über Boden, ebenfalls bergwärts gemessen, hat der Stamm noch $9.7 \mathrm{~m}$, bei $1.5 \mathrm{~m}$ über Boden $8.85 \mathrm{~m}$.

Auf dessen unterer Seite geht, in einer Höhe von zirka $4 \mathrm{~m}$, ein starker Ast von nahezu $1 \mathrm{~m}$ Durchmesser horizontal ab, während der Stamm auf der oberen Seite bis zu 8 m Höhe astfrei ist und seinen breiten, etwas hangabwärts geneigten Rücken mit schwacher Windung nach rechts zeigt. (Hierzu nebenstehendes Bild.) In erwähnter Höhe teilt sich der Hauptstamm in drei Stämme, breite Einsattelungen bildend. Die meisten Äste sind dem Stamme (wie gewöhnlich an Berghängen) auf der untern Seite angesetzt.

Die blättrige, hellbraune Rinde, in welche Namen eingeschnitten sind und welcher hie und da dunkelgrünes Moos (Leucodon sciuroides) anlıaftet, umkleidet noch die ganze Rundung des Stammes. Forscht man aber näher nach dessen Innerem, unter Benutzung einer etwa 10 bis $12 \mathrm{~cm}$ weiten Öffnung, so verliert sich ein $2 \mathrm{~m}$ langer Bergstock, ohne die gegenüberliegende Wandung der ausgefaulten Höhlung zu erreichen, und dessenungeachtet tragen einzelne Äste noch reichlich Früchte.

Vom Stock aus strecken sich abwärts starke Wurzelstränge über den Boden hin, und rings um denselben legt sich grüner Rasen an. In einer kleinen Bucht blühten den 22. Mai 1900 weisse Anemonen (anemone nemorosa L.). Die Baumkrone war zu dieser Zeit noch blattlos, die Knospen fingen eben erst an zu schwellel1. Sie hat 24-25 $\mathrm{m}$ im Durchmesser und ist infolge ihres hohen Alters stark gelichtet.

In seiner vollsten Grösse und Majestät zeigt sich der Ahorn in einiger Entfernung von SSO, während die photographische Aufnahme von einer etwas erhöhten Stelle von NO stattfand (den 24. Juli 1899).

Vom freien Standpunkt des Baumes aus, unter den Felsen des Widderfeldstocks, dringt der Blick bis zu linterst ins Melchtal, wo das sog. Tannenband oder der Hohstollen mit der Hohmattspitze sich in die Quere legt. Rechts davon ragt das schwarze pyramidale Brünigshaupt empor $(2314 \mathrm{~m})$, auf welches die felsgebänderte Rämisfluh folgt und der Arnigrat. Nordwärts ist am rechtsseitigen Talhang der rüfezügige Schildberg sichtbar, und in der Ferne guckt noch der Pilatus hervor. Durch die Tiefe des Tales, welches die Melchaa ausgewaschen, wird der Blick zum freundlichen Sarnen hingeleitet mit seinem Landenberg.

\title{
Tafel IV. Die Esche von Morillon bei Bern.
}

\author{
(Fraxinus excelsior L.)
}

Auf einer grossen, ebenen Wiese des Landgutes Morillon bei Bern, am nördlichen Fuss des Gurten, nahe der Strassen- und Tramlinie, die von Bern nach Wabern führt, steht obige 
Esclıe in voller Freiheit zur Entwickelung ihrer lndividualität. lhr Stamm misst nahe dem Boden $3.9 \mathrm{~m}$ im Umfang, bei $1.5 \mathrm{~m}$ über Boden noch $3.6 \mathrm{~m}$. Diese Stärke behält er annähernd bei bis in eine Höhe von $4 \mathrm{~m}$, wo er sich gabelt, ohne dass jedoch die Krone deshalb ihre Schönheit verlöre. Dieselbe misst in der Richtung von Süden nach Norden $21 \mathrm{~m}$, von Nordost nach Südwest $24 \mathrm{~m}$, bei nur $20 \mathrm{~m}$ Baumhöhe. Der Stamm und die obere Seite der Äste sind mit tiefdunkelgrünem Moos belegt, das aber immer noch zahlreiche Stellen frei lässt, wo die schöngegitterte Zeichnung der Rinde deutlich sichtbar wird. Das Wachstum des Baumes ist ein äusserst kräftiges und die ganze Erscheinung desselben eine imposante. Die Eigentümlichkeit des gefiederten Laubwerks der Esche tritt am schärfsten und zierlichsten hervor, wenn dasselbe lichtumflossen und durchleuchtet vom reinblauen Himmel absticht.

Über die Geschichte und das Alter der Esche ist nur so viel bekannt, dass ein Gärtner des Gutes Morillon, der vor etwa 24 Jahren als siebzigjähriger Greis gestorben, die junge Pflanze als Knabe aus dem nahen Walde hierhor versetzte. Der Baum besitzt somit ein Alter von nahezu 87 Jahren.

Von ihrem Standpunkt aus (539 m über Meer) beherrscht der Blick die Südseite der auf dem hohen Aarerain stehenden Stadt Bern, aus welcher das Bundeshaus mit seinem prachtvollen Mittelbau stolz hervortritt. Mehr rechts überragt der Münsterturm weit die Häuserreihen. $1 \mathrm{~m}$ Westen erglänzen die begletscherten Berneralpen vom Eiger über das Finsteraarhorn zum Schreck- und Wetterhorn.

(Aufgenommen im Oktober 1899, gemessen 1907.)

\section{Tafel V. Zigeuner-Eiche bei Ramsen.}

(Quercus pedunculata Ehrh.)

Etwa 800 m nördlich von Ramsen, Kanton Schafflausen, entfernt, kurz bevor man in den Ramser-Gcmeindewald an Schüppel gelangt, steht die Zigeuner-Eiche, 418 m über Meer hart am Wege nach Gottmadingen. In ihrem Schatten lagerten sich oft Zigcunerbanden auf ihren Wanderungen, woher die Eicle auch ihren Namen erhalten. 1870 erlitt sie bei einer solchen Lagerung, und später durch sonstiges frevelhaftes Feuern, Brandbeschädigungen, welche ein Aufaulen des Stammes zur Folge liatten. Auf wiederholtes Ansuchen der kant. Forstverwaltung wurde der Stamm 1906/7 ausgemauert, um ihn vor weitern inneren Schädigungen zu schützen, und mit einer eichenen Ruhebank vcrsehen. Von hier aus geniesst man einen freien Ausblick über das Bibertal und nach den Steilhängen des Schienerberges.

Nach Überlieferung soll 1770 unter diesem Baume der Kaufvertrag zwischen Österreich als Verkäufer und dem Stande Zürich als Käufer der Gemeinde Ramsen abgeschlossen worden sein, was indes einer geschichtlichen Begründung entbehrt.

1870 feierte die Gemeinde Ramsen unter der Eiche das Jubiläum ihrer hundertjährigen Zugehörigkeit zur schweizer. Eidgenossenschaft.

Sehr zu bedauern ist, dass, um einer dicht neben diesem alten, stattlichen Baume angepflanzten Linde aufzuhelfen, und zur Spannung der Telegraphendrähte (!), einige mächtige Äste abgehauen und dadurch der Schönheit des Kronenbaucs Eintrag getan wurde.

Die im übrigen noch vollkommen gesunde Zigeunereiche besitzt, nach Messungen vom Januar 1908, im Stammumfang bei $1.2 \mathrm{~m}$ (iiber Boden) $4.9 \mathrm{~m}$, in die Höhe $20.5 \mathrm{~m}$, und die Baumkrone im Durchmesser $20 \mathrm{~m}$.

\section{Tafel VI. Rotbuche bei Flims.}

(Fagus sylvatica L.)

Die ausgedehnte, wellig-hüglige Gegend von Flims (in Graubünden), im Vorderrheintal, die grösstenteils mit Wald bedeckt ist, ans dem einige kleine Scespiegel hervor- 
schimmern und wo die Kuranstalt "Waldhäuser" einen der obersten Hügel einnimmt, besteht aus einer enormen Schuttmasse, die ein Bergsturz vom Segnas herunter hier angehäuft. Unsere Buche ist diesem kalkreichen Boden entwachsen und steht unter den Waldhäusern, bei Chivreu, etwa 1030 m über Meer, am nordöstlichen Hang einer kleinen Mulde, unweit dem Flembache, nach zwei Seiten frei, im übrigen durch andere Bäume gedeckt.

Es ist eine der schönsten Rotbuchen der Schweiz. Sie besitzt eine Höhe von $26 \mathrm{~m}$ und misst bei $1.20 \mathrm{~m}$ über Boden noch $5.30 \mathrm{~m}$ im Umfang. Der Hauptstamm, dessen Fuss dicht mit Moos überwachsen ist, teilt sich in geringer Höhe in vier Unterstämme, die aber, vereint, eine regelmässige, schöngewölbte Krone mit prächtigen Auslagen bilden, ohne die reiche Beastung ganz zu decken. Sie misst $25 \mathrm{~m}$ im Durchmesser.

Aus dem Massengehalt einer im Winter 1897 in Chivreu gefällten, ziemlich gleich grossen Buche zu schliessen, mag die Buche unseres Bildes etwa 34 Festmeter enthalten. Obwohl das Alter des Baumes um 300 Jahre betragen mag, scheint er noch kerngesund zu sein und trägt in günstigen Jahrgängen noch reichlich Frucht.

\title{
Tafel VII. Die Schwarzpappel in Siebnen (Kanton Schwyz).
}

\author{
(Populus nigra L.)
}

Da, wo das Wäggital in die Ebene von Lachen-Wangen ausmündet, liegt mitten in einem grossen Obstgarten, von der Wäggi-Aa durchflossen, die grosse industriereiche Ortschaft Siebnen. Nach Urkunden, die bis 1601 zurückgehen, war dieselbe früher Siebeneich benannt, von einer längst schon eingegangenen Rieseneiche, die sich aus 7 Stämmen aufbaute.

Auch die Schwarzpappel unseres Bildes soll mit anderen ihrer Art schon zur Zeit der Rieseneiche in dortiger Gegend, in der Nähe einer Getreidemühle mit Säge und einigen Häuschen gestanden haben. Nach der Korrektion der Aa liegt nunmehr ihr Standort am rechten, etwas erhöhten Ufer derselben, $454 \mathrm{~m}$ über Meer. Ein Fussweg führt an ihr von der Brücke nach der nahen Fabrik Wirth \& Kunz, deren Eigentum sie ist. Eine Bank umschliesst die nördliche Hälfte des Stammes. Dieselbe wurde in den letzten 30-40 Jahren so stark vom Baum überwallt, dass sie schon zweimal freigemacht werden musste. Auch die Gasleitung, die an der Pappel zu einer Lampe führt, die an ihr angebracht ist, liegt gegenwärtig tief unter der Rinde.

Die stattgefundenen Messungen im Jahre 1900 des noch im kräftigsten Wachstum stehenden Baumes ergaben: Höhe $26 \mathrm{~m}$, Umfang nahe dem Boden $5.50 \mathrm{~m}$, bei $1.50 \mathrm{~m}$ über Bodell $4.50 \mathrm{~m}$. Der Stamm mit tiefgefurchter Rinde ist astrein bis $\mathrm{zu} 8 \mathrm{~m}$ Höhe. Das Alter der Pappel darf bei ihrem starken Wachstum höchstens zu 150 Jahren angenommen werden.

Ein grosser Ast der Pappel (links im Bild) reicht über die Aa fast bis an das jenseitige Ufer hinüber. Eine Abzweigung desselben, die fast bis in die Wellen der Aa herunterhing, wurde abgehauen, weil man das Abreissen des ganzen schweren Astes vom Stamm weg befürchtete.

Die Krone trägt den ausgeprägten sperrigen, der Schwarzpappel eigenen Charakter, ihre Belaubung ist gräulich glänzend, und scharf tritt die schwarze, starke Beastung aus derselben hervor. Der Baum hat reiche Auslagen in schön abgerundeten Gruppen, und seine Wurzeln greifen tief in das von der Aa bespülte frische Ufer.

Die Schwarzpappel (im dortigen Dialekt Soorenbaum, anderwärts Saarbaum benannt) gilt in Siebnen auch als Barometer, indem ein schwaches Zittern ihrer Blätter über der Aa schönes Wetter anzeigt, starkes Schwanken der grossen Äste stürmische Regen, und ruhige Belaubung, ohne dass zwischen 5 und 6 Uhr abends vom Wäggital ein Lüftchen weht, regnerische Witterung.

Den Knospen der Schwarzpappel sollen in früheren Zeiten wundertätige Heilkräfte zugeschrieben worden sein. 


\section{Tafel VIII. Linde von Scharans.}

(Tilia platyphyllus Scop.)

In noch höherem Alter als die Linde von Freiburg steht diejenige von Scharans im Domleschg, Kanton Graubünden. Sie ist eine Altersgenossin des 1870 vom Sturm geworfenen Tronser-Ahorns, unter dessen Krone 1424 der Obere oder Graue Bund beschworen wurde. Im „patriotischen Magazin von und über Bünden, als ein Beitrag zur näheren Kenntnis dieses auswärts noch so unbekannten Landes", schreibt H. L. Lehmann 1790 über die Scharanser Linde:

„Eine Merkwürdigkeit ist die neben der Kirche stehende Linde, welche aus einem aus Holz geschnitzten Rhetus-Bilde umhalset wird. Unter ihrem Schatten werden alle Nachbarschaftssachen in Überlegung genommen und die Dorfversammlungen gehalten. Schon im Jahre 1403 wurden, laut eines vorhandenen pergamentenen Briefes, vom Dorfmeister (Cuvig) und Nachbauern zu Scharans unter der Linde neben der Kirche gemehret." 1

Arnold Nüscheler sagt in „Die Gotteshäuser der Schweiz, historisch antiquarische Forschungen, erstes Heft, Bistum Chur “, gedruckt in Zürich von Orell Füssli \& Cic. 1864, auf Seite 97, nachdem er zunächst der allen Heiligen geweihten Kirche Erwähnung getan, deren vorzüglichste Zierde das Grabmal des Ulrich von Marmels sei, Magister der freien Künste und evangelischen Predigers daselbst $(\dagger$ 6. Juni 1531 an der Pest): „Neben der Kirche steht eine riesige, höchst merkwïrdige Linde, deren Alter auf 600 Jahre berechnet wird."

Nach einer Urkunde im Scharanser Archiv von 1740, März 23., fasste die Nachbarschaft Scharans unter der Linde den Beschluss, während 41 Jahren keine neuen Nachbarn mehr aufzunehmen.

Auch die im genannten Archiv enthaltenen Protokolle über die Wahlen der Cuvige (Dorfmeister) besagen, dass dieselben im XV11I. Jahrhundert noch unter der Linde abgehalten worden seien.

In den bündnerischen Monatsblättern (neue Folge) 1903, Nr. 5, gibt Prof. Chr. Brügger eine Beschreibung der Scharanser-Linde, die an Grösse, Alter und Reichtum historischer Erinnerungen die grosse Linde in Churwalden übertreffe. Unter deren Laubdach sei schon vor mehr denn 450 Jahren "gemeindet" worden, zu einer Zeit, wo die berühmten Appenzellerund Freiburger-Linden noch nicht vorhanden waren. Sie möge ein Alter von 600-700 Jahren besitzen und zur Zeit der letzten Freiherren von Vatz gepflanzt worden sein.

Nach dem Bilde unserer Linde haben wir einen immer noch kräftigen, frei-, ohne jegliche Stütze feststehenden, gewaltigen, schönen Baum vor uns, der in dem herrlichen Klima des fruchtbaren und landschaftlich so schönen Domleschg vorzüglich gediehen ist. Die Rinde umschliesst den $5.90 \mathrm{~m}$ in Umfang (in Brusthöhe) messenden Stamm noch vollkommen ohne Lücke. Er teilt sich bei zirka $2 \mathrm{~m}$ Höhe in zwei Hauptäste, sofern er nicht aus zwei, von Grund aus unter sich verwachsenen Stämmen besteht. Der südwärts geneigte Arm misst noch $3.65 \mathrm{~m}$, der nördliche $3.86 \mathrm{~m}$ im Umfang. Letzterer teilt sich bald wieder in zwei Unteräste. von welchen der eine abgebrochen ist, aber reichlich Ausschläge getrieben hat. Der südliche Ast erster Ordnung ist zu dem hervorragenden obersten Wipfel emporgewachsen, wölbt sich aber nicht zu der, der Linde sonst eigentümlichen Kuppel. Unten am Boden ist der Stock an einigen Stellen etwas angefault. Der grösste Kronendurchmesser beträgt $20 \mathrm{~m}$.

Die Linde steht mitten auf dem schwach westlich geneigten Platz, südwestlich der Kirche, ausserhalb des Kirchhofes, unweit unter dem Schulhaus und, wie das Bild zeigt, ob einer Stallung alter Bauart. Die Gemeindeversammlungen finden nicht mehr unter der Linde, sondern im Schulhaus statt, aber auf einer an der untern Seite des Stammes angebrachten Tafel werden die amtlichen Bekanntmachungen angeschlagen.

(Die Aufnahme und Messung der Linde fand 1907 statt.)

1 Lehmann bemerkt hiebei, dass der in der Bindnergeschichte so berüchtigte, aber lange noch nicht genug bekannte Jörg Jenatsch in Scharans kurze Zeit Pfarrer gewesen sei (von 1617 oder 1618 an). 


\title{
Tafel IX. Akazie von Bern.
}

(Robinia pseud-acacia Linné.)

Auf dem Spitalacker in Bern, da wo die Spitalacker- und die Beundenfeldstrasse sich kreuzen, gegenüber dem Primarschulhaus, steht die Akazie unseres Bildes, etwas in das Trottoir vortretend. Sie hat in Nordamerika ihre Heimat. Sie soll in den ersten Jahren des vorigen Jahrhunderts, als die Stadt sich noch nicht so weit ausdehnte, gepflanzt worden sein und wäre somit etwa 100 Jahre alt. Beim Bau genannter Strassen lief sie Gefahr gefällt zu werden, und verdankt ihr Leben nur der Fürsprache der Vorsteherin des nahegelegenen Mädcheninstituts Waldheim. Sie kam beim Strassenbau etwa $60 \mathrm{~cm}$ tiefer in den Boden zu liegen als früher, ohne indes darunter zu leiden.

Etwa $2-3 \mathrm{~m}$ ïber Boden teilt sich der Stamm in mehrere kleinere und grössere Äste, ohne einen eigentlichen Hauptstamm: Zwei der stärksten Äste sind in verschiedenen Höhen, wahrscheinlich durch Schnee gebrochen worden, haben aber wieder ausgeschlagen, sodass die Krone sich dennoch ziemlich regelmässig aufbaut.

Wie dies auf dem Bilde deutlich ersichtlich, ist der Stamm von oben nach unten von stark erhabenen Wulsten durchzogen, er ist spannrückig. Er misst heute bei $1.20 \mathrm{~m}$ über Boden $3.75 \mathrm{~m}$ im Umfang und $21.50 \mathrm{~m}$ in der Höhe und steht $566 \mathrm{~m}$ über Meer.

Leider hat die Verwaltung des Elektrizitätswerkes der Stadt Bern bei Spannung ihrer Leitung diesem Baume keine Rücksicht getragen. Die Drähte ziehen sich mitten durch dessen Krone hindurch, und alle Äste, welche der Leitung zu nahe kamen, wurden entfernt. Damit nicht genug, musste die Akazie auch noch dazu herhalten, durch einen an ihr befestigten Draht einen Telegraphenmast $z u$ stützen. Künftighin wird hoffentlich der Verein für Naturschutz sich auch der schönen Bäume der Schweiz annehmen.

\section{Tafel X. Der Wallnussbaum im Gwatt bei Thun.}

\author{
(Juglans regia L. Jovis glans, Jupiters Eiche.)
}

Wenn man sich von Thun aus in südlicher Richtung gegen Wimmis begibt, schweift der Blick über eine grossartige Gebirgslandschaft. Zunächst vor uns zieht sich die schroffe Stockhornkette gegen Bern hin, weiter östlich schiebt sich der Niesen vor und über den Spiegel des Thunersees hinweg schaut man im Hintergrund die gewaltigen Gletscher- und Felswände der Gebirgskette von der Blümlisalp bis zum Schreckhorn hin. Links über dem See liegt das Plateau des Beatenberg und zieht sich der zerrissene Sigriswilergrat nach Nordosten.

Kurz bevor man die Ortschaft Gwatt erreicht, breitet, hart links der Strasse, die Rieseneiche ihre Krone aus, deren Bild Tafel XV und XVl enthält; im Dorfe selbst ist es unser Nussbaum, vor dem wir bewundernd stehen bleiben.

Eine kleine Wiesenfläche, umgeben von vereinzelten bescheidenen bäuerlichen Wohnungen $565 \mathrm{~m}$ ü. $M$. ist der Standort des Nussbaums, dessen Wurzeln sich in einem kiesigen, fruchtbaren Alluvialboden ausbreiten. Er misst nahe am Wurzelanlauf $6.7 \mathrm{~m}$ im Umfang, bei $1.2 \mathrm{~m}$ (über Boden) $5.47 \mathrm{~m}$, bei $1.8 \mathrm{~m}$ wieder 6.2 . Seine Höhe beträgt $20 \mathrm{~m}$. Bei $3 \mathrm{~m}$ (über Boden) gehen, ohne eigentlichen Hauptstamm, sechs starke Äste aus, die sich während Jahrhunderten, raum- und lichtsuchend, $\mathrm{zu}$ einer gewaltigen, herrlichen Krone gestaltet. Das dem Nussbaum eigentïmliche, hellbraune Rindenrelief tritt an Stamm und Ästen scharf hervor und den Astachseln und der oberen Seite der Äste hat sich eine dunkelgrüne bis schwärzliche Moosdecke angelegt.

Der alte Baum vermag seine Säfte nicht mehr in seine äussersten Kronenspitzen hinaufzutreiben, schon seit 20 und mehr Jahren wird ein Absterben von Zweigen beobachtet. Aber 
gerade diese dürren, sich vom blauen Himmel so scharf abhebenden Ästchen gaben dem Baume einen besonders malerischen Reiz. In letzter Zeit hat man sie leider abgeschnitten in der irrigen Meinung, das Bild des Baumes zu verschönern.

Seine Krone hat den bedeutenden Durchmesser von $30 \mathrm{~m}$ und somit eine Trauffläche von 700 Quadratmetern.

Des edlen Wallnussbaumes Heimat liegt in Griechenland und von der Balkanhalbinsel über Transkaukasien, Armenien und Persien bis nach Nordindien. Verwildert soll er in Bosnien und anderwärts vorkommen. Eingeführt wurde er bei uns schon zur Römerzeit und ist als vollkommen akklimatisiert nnd eingebürgert zu betrachten.

\title{
Tafel XI. Die Lärche von Blitzingen
}

\author{
(Larix europaea Dec.)
}

steht gegenüber dem kleinen Bergdorf Blitzingen, des Bezirks Goms, in Oberwallis, unweit $\mathrm{ob}$ dem an der jungen Rhone liegenden Hofe Bodmen, $1350 \mathrm{~m}$ über Meer. Blitzingen ist im Hintergrunde des Bildes sichtbar.

Der Baum ist auf einer schmalen Terrasse, am Fusse des nordwestlichen Talhanges in tiefgründigem, frischem, humosem Lehmboden, mit Kies als Untergrund zu einer der stärksten Lärchen der Schweiz herangewachsen, denn sie mass schon 1896, nahe dem Boden $8.7 \mathrm{~m}$, bei $1.3 \mathrm{~m}$ (iiber Boden) noch $7.5 \mathrm{~m}$ im Umfang, breitete ihre Krone aber nur $10 \mathrm{~m}$ weit'aus. Ihre Länge betrug damals und beträgt gegenwärtig noch $29 \mathrm{~m}$. Der Wipfel ist dürr, der Stock stark angefault, und ihr Alter daher nicht genau zu ermitteln, doch darf dasselbe zu 500 Jahren angenommen werden. An dem ziemlich steilen Hange ob der Lärche findet sich noch eine Anzahl starker Stämme dieser Holzart und reichlich mit Flechten behangene uralte Fichten. Der Stamm steht frei in einer Weide, aber überall um ihn herum sind Lärchen angeflogen.

An der schweiz. Landesausstellung in Genf, 1896, fand sich im forstlichen Pavillon die Scheibe einer Lärche aus dem Walliser Saas-Fee, auf der man 800 Jahrringe zählte. Mit Zettelchen steckte man auf der Scheibe die Hauptperioden der Geschichte der schweiz. Eidgenossenschaft ab und es ergab sich, dass die Lärche zur Zeit der Gründung derselben, 1291, bereits einen Durchmesser von $30 \mathrm{~cm}$ besass.

(Die photographische Aufnahme und die Messungen fanden 1896 statt.)

\section{Tafel XII. Fichte (Rottanne) von Stiegelschwand bei Adelboden (Kt. Bern).}

(Picea excelsa Link.)

Die Fichte ist die in der Schweiz verbreitetste Holzart; sie steigt annähernd bis $1800 \mathrm{~m}$ ins Gebirge hinauf. In den geschlossenen Waldungen der tiefern Lagen verhindert Raumund Lichtmangel die Fichte, eine reiche Krone anzusetzen; aber in den lichtern Beständen, gegen die Waldvegetationsgrenze hin, entwickelt sich dieselbe immer mehr und erreicht ihren charakteristischen Habitus, ihre grösste Schönheit und Vollkommenheit im ¿ganz freien Stand auf den Berg- and Alpweiden in der Gestalt der sog. Schirm- oder Wettertanne.

Unsere Fichte von Stiegelschwand ist eine solche Schirmtanne in vollsten Sinne des Wortes. Vom nahen Sommerkurort Adelboden wird sie oft besucht und ist weit ins Land hinaus als ein ausserordentlicher Baum bekannt.

Ihre Geburt geht jedenfalls in eine sehr entfernte Vergangenheit zuriick. Der Besitzer des Baumes, ein 72 jähriger Greis, sagte aus, er kenne die Tanne von frühester Jugend an, 
aber es komme ihm vor, sie sei immer gleich geblieben. Sie wird wohl schon seit 300-400 lahren dastehen, trägt dieselben aber noch leicht, denı ihr Äusseres lässt, trotz Stürmen und Wetter, denen sie ausgesetzt war, noch auf eine kernhafte Gesundheit schliessen.

Sie steht $1480 \mathrm{~m}$ iiber Mcer auf einer süd-südöstlichen, schwach geneigten Weide und wurzelt in ziemlich fruchtbarem Boden mit Niesenflysch als Untergrund. Unweit unter ihr schäumt der Allenbach zu Tal und im Westen ragen die zerrissenen Felsgräte des Gsür, Albrist- und Scewlenhorns bis über $2700 \mathrm{~m}$ empor.

Treten wir unserer Schirmtanne näher, so fällt uns die äusserst dichte Verzweigung ihrer Krone auf, an der eine Menge Zapfen hängen. Die Äste biegen sich bis fast auf den Boden herunter, und bücken wir uns, um in das Innere einzudringen, so bemerken wir unten an Stamme Stumpen abgehauener Äste, deren Gezweige früher den Boden berührt haben musste.

Schauen wir deın Stamm entlang in die Höhe, so erblicken wir ein merkwürdiges Gewirr schlangenartig verbogener und verschlungener Äste. Sie sind meist abwärts gewendet, an ihren äussersten Enden aber wieder aufwärts gerichtet. Einer der Äste erreicht, nach allen scincı1 Windungen gemessen, eine Länge von $11.5 \mathrm{~m}$, steht aber mit seiner Spitze doch nur 7.4111 vom Stamme ab.

Es haben sich aus Seitenästen zwei Nebenstämme gebildet, von denen der eine $3 \mathrm{~m}$, der andere etwa $18 \mathrm{~m}$ über Boden dem Hauptstamme ansitzt. Vom ganzen Stamme gehen 290 Ästc $a b$, nicht inbegriffen dic obersten am $2 \mathrm{~m}$ langen Wipfel. Die untersten Äste haben einen dirchschnittlichen Umfang von $70 \mathrm{~cm}$.

Durch diesen Astreichtum hat sich eine gewaltige Krone gebildet, die aber durch die 2 Nebenstännne eine etwas unregelmässige Form erhalten hat. Deren Durchmesser von $16 \mathrm{~m}$ entspricht cine Grundfläche von $201 \mathrm{~m}^{2}$, so dass unter unserer Fichte von Stiegelschwand eine kleine Herde Schutz und Schirm gegen Sonne und Wetter findet. Der Stamm hat, bei $1.2 \mathrm{~m}$ über Boden gemessen, einen Umfang von $4.7 \mathrm{~m}$, nahe dem Boden $6 \mathrm{~m}$. Seine Höhe beträgt $25 \mathrm{~m}$.

\title{
Tafel XIII. Die Nordmanns-Tanne bei Genf.
}

\author{
(Abies Nordmanniana Lk.)
}

An der Lausannerstrasse, cine halbe Stunde von Genf entfernt, befindet sich die Villa Pierrière des Herrn William Barbey-Boissier, auf Gebiet der Gemeinde Pregny. Der frühere Besitzer, der bekannte Botaniker Edmond Boissier hat hier von 1850 bis 1865 ein sehr reiches Arborctum angelegt. Der Park vor dem Wohnhaus senkt sich südlich zum Ufer des Genfersees von 395 m zu 375 m hinunter. Die Villa bietet cinen herrlichen Ausblick über den See und iiber das Gebirge Savoiens von Salève, über die Voirons und die Dent d'Oche bis zur Mont-Blanc-Gruppe.

Auf diescm schönen Fleck Erde pflanzte E. Boissier, etwa 1860, die Nordmanns-Tanne unseres Bildes, die somit gegenwärtig ca. 50 Jahre zählt. Diese Kaukasierin hat sich in diesem milden Klima und auf gutem, quartär erratischem Lehmboden, ganz normal zu einem schon stattlichen spitzwalzigen Baum von ca. $20 \mathrm{~m}$ Höhe, $2.22 \mathrm{~m}$ Stammumfang und $10 \mathrm{~m}$ Kronendurchmesser entwickelt und bildet, neben vielen ausländischen Holzarten eine Zicrde des Parkes.

(Photographische Aufnahme und Messung von 1907.)

\section{Tafel XIV. Die Zeder von Beaulieu.}

\section{(Cedrus Libani Loud.)}

Dic Campagne Beaulieu liegt 1/4 Stunde ob der Genfer Eisenbahnstation, $403 \mathrm{ml}$ über Meer. Auf der westlichen Seite des Hauses erheben sich 2 libanotische Zedern, von denen die cine bei freierem und sonnigerem Stand sich zu einem Baum von seltener Grösse und 
Schönheit entwickelte, während die andere, in weniger günstigem Standort für ihre Astbildung ihre Schwester dagegen an Höhe übertrifft.

Über beide Bäume enthält das Fremdenbuch der Campagne folgende Bemerkung: „Les cèdres de Beaulieu ont été plantés en 1735 et proviennent (ainsi que le cèdre du Jardin des Plantes à Paris et Kew) de graines rapportées du Liban par M. Bernard de Jussieu et données par lui au propriétaire de la campagne. ${ }^{1}$ En 1808 , ils étaient déjà d'une grosseur très remarquable.

$M$. le professeur Thury les a mesurés en 1857. A cette époque, le cèdre le plus éloigné de la maison avait en hauteur $27.56 \mathrm{~m}$ et une circonférence de tronc à $1 \mathrm{~m}$ au-dessus du sol de $4.24 \mathrm{~m}$ (diamètre $1.35 \mathrm{~m}$ ) et au-dessous de la première branche de $3.85 \mathrm{~m}$. Le cèdre le plus rapproché de la maison, d'une hauteur de $24.60 \mathrm{~m}$, avait une circonférence de $3.52 \mathrm{~m}$ ou un diamètre de 1.12 m."

H. Correvon sagt in seinem Werke "Nos arbres", S. 100: "D'Angleterre, ou ils ne tardèrent pas à se multiplier, les cèdres passèrent en France et en Suisse. Jussieu importa du Chelsea (au sud de Londres) et non du Liban, comme le veut la légende, des graines de cèdres et les sema au jardin des plantes de Paris, vers 1730. En 1736, il en donna quelques plantons au baron de Sellon, propriétaire de la Villa Beaulieu, près Genève etc."

Eine im Jahr 1907 vorgenonmene Messung der vordern Zeder ergab: Stammumfang bei $1.20 \mathrm{~m}$ über Boden: $5.11 \mathrm{~m}$, Höhe $27.50 \mathrm{~m}$, Länge der längsten Äste 15.75 und $16.20 \mathrm{~m}$, Durcllmesser der Krone $31 \mathrm{~m}$. Die untersten Äste sind $2.50 \mathrm{~m}$ über Boden angesetzt. Die hintere Zeder hat bei $1.20 \mathrm{~m}$ über Boden einen Umfang von $4.25 \mathrm{~m}$, ist dagegen $2 \mathrm{~m}$ höher als erstere. Der Boden besteht aus fruchtbarem Lehm auf Gletschergeschiebe (Moräne). Da die Zedern 1735 oder 1736 gepflanzt wurden, stehen dieselben jetzt in einem Alter von etwa 172 Jahren. Sie tragen längst schon keimfähigen Samen: auf eine ziemlich bedeutende Entfernung um die Bäume herum ist Anflug vorhanden, auch wurde Samen derselben häufig schon zu Aussaaten verwendet. Alljährlich bedeckt sich die vordere Zeder mit einer Masse von männlichen Blüten, die beim geringsten Luftzug ganze Wolken von Blütenstaub aussenden. Die weibliclieı Blütenkätzchen setzen sich in weit geringerer Anzahl und mehr am obern Teil der Krone an, wo der Zapfen mehr Licht und Wärne zu seiner Entwicklung erhält.

Die Äste dieser Zeder sind so lang und schwer, dass die untersten dem Boden aufliegen würden, wären sie nicht durch Stützen schwebend erhalten. Was den Baum auszeichnet, ist, ausser seiner bedeutenden Dimensionen, die prachtvolle, grossartige Auslage seiner weitausgreifenden, stufigen Beastung, die auf unserem Bilde kräftig hervortritt. Damit vereinigt sich eine erhöhte herrliche Lage mit Aussicht auf die Stadt Genf, den See, den Salève und die Gebirgsgruppen des Montblanc und der Walliser Alpen.

Wenn winterliche Nebel den Baum in Reif hüllen, soll er sich bezaubernd ausnehmen und werden die Abende alsdann vom Gutsbesitzer oft benutzt, um den Glanz dieser Naturerscheinung durch bengalische Beleuchtung noch zu erhöhen. Bei Anlass des Festes des schweizerischen Alpenklubs in Genf, im August 1869, flatterte die eidgenössische Fahne auf seiner Spitze und war die Krone abends, bei Empfang des Klubs, beleuchtet.

\section{Tafel XV u. XVI. Die Bettlereiche im Gwatt.}

(Quercus pedunculata Ehrh.).

Wir haben derselben schon bei Beschreibung des Nussbaumes im Gwatt (Nr. X) Erwähnung getan: sie steht auf dem Wege von Thun nach Gwatt hart links an der Landstrasse. Dieser Örtlichkeit wegen wird sie wohl schon manchen Bettler gastlich, zur Ruhe und Stärkung, unter ihr Laubdach aufgenommen und daher ihren Namen erhalten haben.

1) Alors M. de Sellon, 
Bei vollkommen freiem Stande in einer Ebene, die an das sumpfige, mit Röhricht bewachsene Ufer des Thunersees angrenzt, $565 \mathrm{~m}$ ü. M., in angeschwemmtem kiesigem Lehm fussend, entwickelte sich der Baum zu der bedeutenden Dimension von $8.40 \mathrm{~m}$ Stammumfang nahe dem Boden und $7 \mathrm{~m}$ bei $1.80 \mathrm{~m}$ über Boden. Sein grösster Kronendurchmesser beträgt $26 \mathrm{~m}$, der kleinste $20 \mathrm{~m}$; der längste Ast misst $18 \mathrm{~m}$ und die Höhe des Stammes $21.50 \mathrm{~m}$. Diese Maasse beziehen sich auf die Messung von 1896. 1902 wurde frevelhafterveise auf der Südseite des Baumes ein starker Ast von $2.5 \mathrm{~m}^{3}$ lnhalt abgesägt. Der Frevler wurde zwar empfindlich gebüsst, aber der ästhetische Schaden konnte nicht mehr ersetzt werden.

Wir geben das Bild der Bettlereiche vor dieser Beschädigung und zwar in belaubtem und unbelaubtem Zustande. Zeigt sie sich in ersterem in ihrer ganzen Pracht und Fülle, so gestattet uns ihr Winterbild einen Blick in ihr lnneres, in die eigentümliche Gliederung ihrer starren, eckigwirren, kräftigen Beastung, die hauptsächlich Veranlassung gegeben haben wird, die Eiche als Sinnbild festen Willens und zäher Kraft darzustellen.

\section{Tafel XVII. Die Hängefichte von Richisau.}

(Picea excelsa Lk. viminalis Alströmer-Casparis).

Wenn man im Klöntal, Kanton Glarus, durch den unweit unter Richisau gelegenen Wald hinaufstieg, fiel einem eine Fichte auf, nicht ihrer Schönlheit und Stärke, sondern der Eigentümlichkeit ilırer Zweigbildung wegen. Die Hauptäste bogen sich zwar, wie bei den meisten Fichten auch, vom Stamme weg sich etwas senkend, ab und hoben sich dann wieder gegen die Spitze hin, aber die Zweige breiteten sich nicht, wie gewöhnlich, mehr oder weniger horizontal, fächerförmig aus, sondern hingen schnurdünn und schlaff von den Ästen herab. Daher denn auch die Benennung Hängefichte.

Diese Erscheinung ist zwar keine grosse Seltenheit, war aber bei der Fichte unseres Bildes sehr auffallend ausgesprochen; die hängenden Zweige erreichten eine Länge bis zu $1.60 \mathrm{~m}$.

Leider wurde dieser interessante Baum vom Privateigentümer inı Herbst 1907 niedergehauen, trotzdem er ersucht wurde, denselben der Gegend als eine Naturdenkwürdigkeit zu erhalten und ihm hierfür sogar Fr. 100 angeboten wurden.

\section{Tafel XVIII. Arve von Muottas da Celerina (Oberengadin).}

(Pinus Cembra L.).

Die Arve (Zirbelkiefer) ist eine Nadelholzart, die in Mitteleuropa und den Karpathen, oft gemeinschaftlich mit der Lärche, die höchsten Gebirgswaldungen bildet und in Sibirien in der Varietät der sibirischen Zeder (Pinus Cembra sibirica Hort.) ausgedehnte Flächen bedeckt. Unseren Hochalpen ist sie so vorzüglich angepasst, dass ilır hier keine andere Holzart der Erde gleichkommt. Sie trotzt den Unbilden der Witterung in den ausgesetztesten Lagen und heilt Beschädigungen, welchen sie hauptsächlich in Gebieten von Steinschlägen und Lawinen so sehr ausgesetzt ist, durch ihre Reproduktionskraft mit ausserordentlicher Leichtigkeit.

$1 \mathrm{~m}$ Oberengadin hat sich die sonst wegen Mangel an Schutz und Pflege so sehr zurückgegangene Arve in Verbindung mit der Lärche und in den tiefern Lagen auch mit der Fichte in lichten Beständen gut erhalten und steigt in kleinen Gruppen und Einzelstämmen bis $2300 \mathrm{~m}$ empor. Sie verjüngt sich leicht natürlich and wird im Oberengadin schon seit Jahrzehnten und in neuerer Zeit in den gesamten Schweizeralpen reichlich angepflanzt.

Die Arve unseres Bildes steht heute noch so fest als je auf Muottas da Celerina, einem nordöstlichen Ausläufer des Piz Rosatsch gegen Pontresina hin, 2120 m über Meer. Sie wurzelt 
auf einer geologischen Unterlage, die an der Grenze zwischen Glimmerschiefer und Syenit liegt und zu einem sandigen Lehm verwittert. lhre sparrigen, mit dunkelbüscheligem Nadelwerk behangenen Äste breiten sich frei über eine Alpweide aus, am oberen Rande lichter Arven- und Lärchenwaldungen. Rings um die Arve und weit bergwärts derselben, selbst auf dem trockensten, dicht überrasten Boden finden sich zahlreiche junge Arven vor. Die Aussaat nach oben hat unzweifelhaft der Tannhäher besorgt, der den schmackhaften Arvennüsschen leidenschaftlich nachstellt, sich davon Vorräte anlegt, dabei welche im Fluge oder beim Aufhacken verliert, die dann teilweise zur Keimung gelangen.

Die Arve von Muottas besitzt sehr starke Wurzelanläufe und misst unmittelbar über denselben $4.20 \mathrm{~m}$ im Umfang. Gegen Südost gehen sechs starke Äste vom Stamm aus, von denen die zwei untersten, der eine bei $1.11 \mathrm{~m}$, der andere bei $4 \mathrm{~m}$ iber dem Boden dem Stamme angesetzt sind. Der stärkere misst $2 \mathrm{~m}$ im Umfang und 5111 in der Länge. Nach Nordwesten gehen in einer Höhe von 1.06-5 m über Boden fünf Äste aus, wovon einer als dürrer Stumpen. Da ausser dem astigen, hoch oben gabelnden Hauptstamm, auch erwähnte zwei Astgruppen stammig emporwuchsen, so haben sich drei Kronen zu einer gemeinschaftlichen vereinigt, die einen Durchmesser von $16.50 \mathrm{~m}$ besitzt. Der Baum erreicht nur eine Höhe voln 15-16 m. Die Borke des Stammes ist stark mit bunten Flechten bedeckt. Das Alter der scheinbar noch gesunden Arve ist schwierig zu bestimmen, wird aber zu 500-600 Jahren angenommen werdell dürfen.

Von Pontresina aus gelangt man auf bequemem Fusspfad in einer leichten Stunde auf Muottas da Celerina, von wo sich eine herrliche Aussicht auf die umliegende Hochgebirgslandschaft darbietet.

\section{Tafel XIX. Säulenfichte an der Ofenbergstrasse.}

(Picea excelsa Link, lusus columnaris Carrière.)

Wenn man sich von Zernez, im Unterengadin, nach dem Ofenberg begibt, so durchquert man zunächst das kleine Tal Barcli und dann das grössere von Laschadura, von wo der Weg in südlicher Richtung in die sogen. Taglieda umbiegt. Hier erhebt sich, in westlicher Lage, 1770 m über Meer, hart unter der Landstrasse unsere Baumgruppe mit der Säulenfichte. Letztere steht mitten im Bilde, nach rechts mit anderen Fichten vergesellschaltet, die aber nicht die so scharf ausgesprochene Spitzsäulen- oder sogar Nadelform besitze11. Zunächst links der Fichte steht eine Engadiner-Kiefer (Pinus silvestris var. engadinensis) und mitten im Vordergrunde der Gruppe, hart unter der Strasse, eine junge Arve. Wir haben somit einen Mischwald von Fichten, Kiefern und Arven vor uns. 'Das Gebirge, das sich im Hintergrunde zeigt, ist die rechte Seite des Val Laschadura mit dem Gebirgstock des Piz Nuna (3126 m). Der Untergrund, auf dem die Gruppe sich angesiedelt, besteht aus den Lünerschichten, die dem Hauptdolomit nahe stehen und zu einem kalkhaltigen, trockenen Boden verwittern.

Der Standort der Spitzwalzenfichte ist sonach ein hochgelegener, den Westwinden ausgesetzter, rauher, mit wenig fruchtbarem, trockenem Boden, so dass die Äste der Fichte während der ohnedem kurzen Vegetationszeit in ihrer Entwicklung kỉmmerten und kurz blieben und in gleichem Masse auch die einfache, gedrängte, dicht- und kurznadelige Verzweigung. Da erwähnte Lagen im schweizerischen Hochgebirge ziemlich verbreitet sind, so ist auch das Vorkommen der Fichten von der mehr oder weniger ausgeprägten Spitzsäulenform nicht selten.

Die Engadiner-Kiefer, die im Bilde mit ihren Nadelbüscheln einer Arve ähnlich sieht, hat die Botaniker wegen ihrer Beziehungen einerseits zur gewöhnlichen Kiefer und anderseits zur Bergkiefer schon viel beschäftigt. Man scheint sie nun doch als eine Bastardform der beiden genannten Arten anerkennen zıl wollen, was früher bestritten wurde.

(Die photographische Aufnahme der Gruppe fand den 22. Juli 1898 statt.) 


\title{
Tafel XX. Chilenische Araukarie. Araucaria imbricata Pav.
}

\author{
Im sogen. Weinberg ob St. Margrethen, st. gallisches Rheinthal.
}

Als ich 1874 als st. gallischer Forstbeamter im Riesiwald der Gemeinde St. Margrethen $2 u$ tun hatte, bemerkte der mich begleitende Förster, es stehe da oben, im sogen. Weinberg, eine ganz sonderbare, fremde Nadelholzart, die er nicht kenne. Als wir später hinaufstiegen, stund zu meinem nicht geringen Erstaunen eine prachtvolle, durchaus unbeschädigte Araucaria imbricata voll $7 \mathrm{~m}$ Höhe vor mir. Wie ist nun diese, einzig dem Gebirge des sïdlichen Chilis angehörende Baumart hierher gekommen? In Gartenanlagen des Kantons Tessin, am Genfersee und in andern milden Lagen der Scliweiz sieht man sie hie und da, aber hier im Rheintal, in einer Höhe von zirka $550 \mathrm{~m}$ über Meer, war sie mir eine ausserordentliche Erscheinung.

Das Gut Weinberg gehört gegenwärtig den Gebrüdern Albert und Wilhelm Künzler. lhr Vater, Bartholome, hat dasselbe 1849 gekauft und in demselben ein Stickereigeschäft eingerichtet. Geschäftsführer war ein Herr Pulling aus Oldenberg, anf dessen Rat Künzler 1852 und 53 neben dem Haus einen kleinen Park anlegte. Die Pflanzen wurden aus dem botanischen Garten in Zürich bezogen, unter welchen sich auch unsere Araucaria befand, die unterdessen, in den zirka 55 lahren, zu einem Baum von $10.50 \mathrm{~m}$ Höhe und $1.40 \mathrm{~m}$ Stammumfang (bei 1.20 müuber Boden) emporgewachsen ist. Sie nimmt eine nordöstliche, dem Ostwinde und Fölı stark ausgesetzte Lage ein, breitet aber ihre Wurzeln in einem humusreichen, tiefgründigen Lehmboden aus. Früher wurde in der Nähe der Araucaria Weinbau getrieben, woher der Name des Gutes kommt, dann aber aufgegeben, weil der Ertrag zu gering war. Auf das milde Klima dortiger Gegend deutet aber auch das Vorkommen der echten Kastanie im oberwähnten Riesiwald hin, ferner des Besenpfriem (Cytisus scoparius Link), wogegen die in einigen Exemplaren vorkommende rostfarbene Alpenrose (Rhododendron ferrugineum L.) uns an die vorgeschichtliche Gletscherzeit erinnert; sie ist ein Relikt derselben.

Das Klima von St. Margrethen scheint der Araucaria zuzusagen, denn ilıre Benadelung ist üppig dunkelgrün, die Jahrestriebe indes kurz und ihr Baı deshalb ein etwas gedrungener. Der starke Frost des Winters von 1879 auf 80 hatte die Enden der scharf zugespitzten, den Zweig anliegenden Nadeln schwach gebräunt, ohne weitere nachteilige Folgen. Schwerer Schnee biegt die schlangenförmigen, dünnen Äste stark gen Boden, bricht sie aber nicht. Mit Reif bedeckt, soll der kandelaberförmige Baum, im vollen Sonnenschein in den schönsten Farben strahlen.

Schon seit etwa 20 Jahren trägt der zweihäusige Baum die ganz eigenartigen, zirka $12 \mathrm{~cm}$ langen, eiförmigen, mit zahlreichen Schuppen dachziegelförmig bedeckten Zapfen, die aber bisher noch keinen keimfäligen Samen getragen. Der Kern gereifter Früchte ist essbar.

Da der fremdartige, am Wege von St. Margrethen nach Walzenhausen steliende Baum allgemein auffällt, und Zweige als Andenken abgeschnitten wurden, so salı sich der Eigentümer desselben veranlasst, ihn mit einen Zaun zu umschliessen. Die Araucaria steht somit jetzt in guter Hut und die heutigen Bestrebungen für Naturschutz werden sie wohl auch unter ihre Fittige nehmen. 


\section{VERLAG VON A. FRANCKE IN BERN.}

Coaz, J., eidg. Oberforstinspektor, Die Lauinen der Schweizeralpen. Bearbeitet im Auftrag des eidg. Handels- und Landwirtschaftsdepartements. Mit einer Lauinenkarte des Gotthardgebietes, 5 Tabellen und vielen Abbildungen. 2. Ausgabe. Gr. 8. 147 S. 1888. Broschiert, herabgesetzter Preis Fr. 1.50.

- Der Lauinenschaden im schweizerischen Hochgebirge im Winter und Frühjahr 1887-1888. Bearbeitet im Auftrag des Industrie- und Handelsdepartements. $4^{\circ}$. $67 \mathrm{~S}$. mit 1 Tabelle. 1889. Broschiert. Preis Fr. 3. - .

Alpenpässe, Die schweizerischen. lllustriertes Posthandbuch. Herausgegeben von der schreizerischen Postverwaltung, 2. Aufl. mit 156 Illustrationen u. 13 Karten. 1894. Geb. Fr. 7. - .

Bähler, Dr. A., Der Sustenpass und seine Täler. Mit einem Anhang: Das Unglück am Sustenpass in Jahre 1899 von Dr. J. Jegerlehner. Mit 7 Vollbildern in Autotypie und einem Grundriss der Meienschanze. Preis brosch. Fr. 2. - .

Dübi, Dr. Heinrich, Saas-Fee und Umgebung. Ein Führer durch Geschichte, Volk und Landschaft des Saastales. Mit 51 lllustrationen nach Naturaufnahmen, einem Panorama vom Plattje am Mittagliorn von M. Pierre Odier und einer Karte des Saastales (1:50,000), Überdruck aus dem Siegfried-Atlas mit Nachträgen und Korrekturen. Preis geb. Fr. 4. -

- Hochgebirgsfuhrer durch die Berner Alpen. Band 1. (Von der Dent de Morcles bis zur Gemmi.) lm Auftrag der Sektion Bern des S. A. C. K1. 8*. XV1, 111 S. 1907. Preis in hübschem Leinwandband Fr. 3. - .

Friedli, Emanuel, Bärndïtsch als Spiegel bernischen Volkstums. Herausgeg. mit Unterstïtzung der Regierung des Kantons Bern und unter Mitwirkung einer voll ihr bestellten Kommission (Dr. O. v. Greyerz, Oberlehrer Stercli und Prof. Dr. H. Türler, Staatsarchivar des Kts. Bern). Erster Band: „Lïtzelflïh". Mit 158 1llustrationen und 14 Farbendrucken nach Originalen von R. Münger, W. Gorgé, F. Brand, K. Indermühle und nach photographischenl Aufnahmen von Dr. Hegg nebst 2 topographischen Karten der Gemeinde Lützelflülı. Gr. 8. Preis broschiert Fr. 12. - , gebunden in hübschem Originalband Fr. 14. -

- Zweiter Band: „Grindelwald“. Mit 197 1llustrationen und 17 Farbendrucken nach Originalen von R. Münger, W. Gorgé, F. Brand, H. Bleuer und nach plotographischen Originalaufnahmen von Dr. E. Hegg und anderen, nebst 14 lnitialen aus deni 18. Jahrhundert, 1 Karte und 1 Panorania. Gr. 8". Preis brosch. Fr. 12. - , geb. in Originalband Fr. 14. -

Gempeler-Schletti, D., Heimatkunde des Simmentals. Mit 87 lllustrationen und einer Karte des Simmentals. Preis broscl. Fr. 6. -, in hübschem Leinwandband Fr. 7.50.

Haller, Albrecht von, Die Alpen. Prachtausgabe. Mit einer Beilage und 12 zeitgenössischen Kupfern. Dem Andenken Hallers gewidmet von Prof. Dr. Karl Geiser. Preis in GrossQuart auf echtem Handpapier geb. Fr. 10. - .

Jegerlehner, Dr. J., Das Val d'Anniviers (Eivischtal), nebst einem Streifzug ins Val d'Hérens (Evolena). Führer durch Landschaft, Geschichte, Volk nnd Sage eines Walliser Hochtales. Mit einer Photogravure und fünf Zeichnungen nacl E. Bille, 49 lllustrationen nach Natıraufnahmen und zwei graphischen Darstellungen von Prof. Dr. C. Schröter. $8^{\circ}$. Preis kart. Fr. 3. 80, gebunden Fr. 4.--.

- Was die Sennen erzählen. Märchen und Sagen aus den Wallis. Aus dem Volksınunde gesammelt. $8^{\circ}$. V1ll, 221 S. 3. Auflage. 1908. Preis gebunden Fr. 3. 50.

- Am Herdfener der Sennen. Neue Märchen und Sagen aus den Wallis. Aus dem Volksnunde gesammelt. lllustriert von Hannah Egger. 1.--2. Tausend. 8. IV. 256 S. 1908. Preis gebunden Fr. 4. -

Lïthi, E., Die bernischen Chuzen oder Hochwachten im 17. Jahrhundert. Dritte, vermelırte Auflage. $8^{\circ}$. Brosch. Preis 60 Cts.

- Zun eintausendfünfhundertjährigen Jubiläum der Alamannen der Westschweiz. Mit Bilderı aus der Waffensammlung des Schweizerischen Landesmuseums und Zeichnungen von Befestigungen. $8^{\circ}$. 23 S. Broschiert. Preis 60 Cts.

Studer, Gottlieb, Pontresina und Engelberg. Aufzeichnungen aus den Jahren 1826-1863. Festgabe der Sektion Bern des S. A. C. an die Teilnehmer des Klubfestes in Bern, 21. bis 23. Septenber 1907. Preis gebunden in Futteral Fr. 1. 80.

Walser, Dr. Hermann, Die Schweiz. Ein Begleitwort zur eidgenössischen Schulwandkarte. Mit 7 Zeichnungen. $8^{\circ}$. 3. Auflage. 1908, in Leinwand gebunden Fr. 2. - . 


\section{VERLAG VON A. FRANCKE IN BERN. \\ Baum-Album der Schweiz}

GROSSE AUSGABE

Bilder von Bäumen, die durch Grösse und Schönleit hervorragen oder ein besonders geschichtliches lnteresse bieten.

\section{LES ARBRES DE LA SUISSE}

Collection d'arbres remarquables par leurs dimensions, leur beautẻ ou interessants par leur histoire.

EDITION GRAND FORMAT

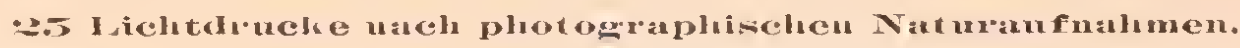

Format, mit Rand, $66^{\circ}>51 \mathrm{~cm}$.

Aufgenomulen im Auftrage des cidg. Departements des Imnern.

Preis $381_{1 \times}$. für das vollständige Werk mlt deutschem oder französischem Text in eleg. Leinwandmappe mit Lederrücken. 3:3 ${ }^{-}$. in einfacherer Mappe mit Leinwandrücken und -Ecken.

- Ein Prachtwerk ersten Ranges für jeden Forstmann!

Jedes der Blätter gibt in einfacher Umrahmung einen prächtigen Wandschmuck ab.

\section{Schweizerische Zeitschrift für Forstwesen}

Organ des Schweiz. Forstvereins.

Redaktion: Dr. F. Fankhauser, Adjunkt des eidg. Oberforstinspektorates, in Bern.

In monatlich erscheinenden illustrierten Heften.

Abonnementspreis per Jahr: Fr. 5 für die Schweiz, Mk. 5 fürs Ausland.

\%eitschrift für Forstwesen und Journal forcstier gleichzcitig abonniert: Schweiz Fr. 7. _ ; Ausland M. 7. - per Jalır.

\section{JOURNAL FORESTIER SUISSE}

Organe de la société des forestiers suisses.

Rédaction: M. Decoppet, professeur à l'école polytechnique fédérale de Zuriclı.

Prix d'abonnement par an: Suisse Fr. 3.-; Etranger M. 3.- .

Editions française et allemande abonnées en mênc temps: Sıissc Fr. 7.—; Etranger M. 7. —.

Studer, Dr. Th. und V. Fatio, Katalog der schweizerischen Vögel. Bearbeitet im Auftrag des eidg. Departements für Industrie und Landwirtschaft (Abteilnug Forstwesen), unter Mitwirkung zahlreicher Beobachter in verschiedenen Kantonen.

I. Lfg.: Tagraubvögel. $8^{\circ}$. (S. $1-100$ mit 7 Karten.) 1889. Brosch. Preis Fr. 3. -

II. „ Eulen u. Spaltschnäbler. 8". (S.101-192 mit 4 Karten.) 1894. Br. Preis Fr.3.-.

III. " Sitzfüssler, Krähen, Klettervögel und Fänger. $8^{\circ}$. (VIII, S. 193-418 mit 2 Karten.) 1901. Broscl. Preis Fr. 5. -.

IV. . Braunellen, Schlüpfer, Wasserstare, Meisen. Bearbeitet von G. v. Burg. 8". (XV, S. 419-601 mit 1 Karte.) Brosch. Preis Fr. 4. 50.

V. " Goldhähnchen, Laubsänger. Bearbeitet von G. v. Burg. 8". (IV, S. $603-741$ mit 1 Karte.) Broscl. Preis Fr. 3. 50.

Studer, Gottlieb, Ueber Eis und Schnee. Die höchsten Gipfel der Schweiz und dic Geschichte ihrer Besteigung. 2. Auflage, umgearbeitet und ergänzt von $D r$. A. Wäber und Dr. H. Diabi. Band 1: Die Nordalpen. Band II: Die Südalpen vom Mont Blanc bis zur Dent du Midi und, weiter bis zur Simplongruppe. Band III: Die SüdaIpen (Schluss) nnd Ostalpen. Preis eines jeden Bandes in hübschem Leinwandeinband Fr. 8. -. 


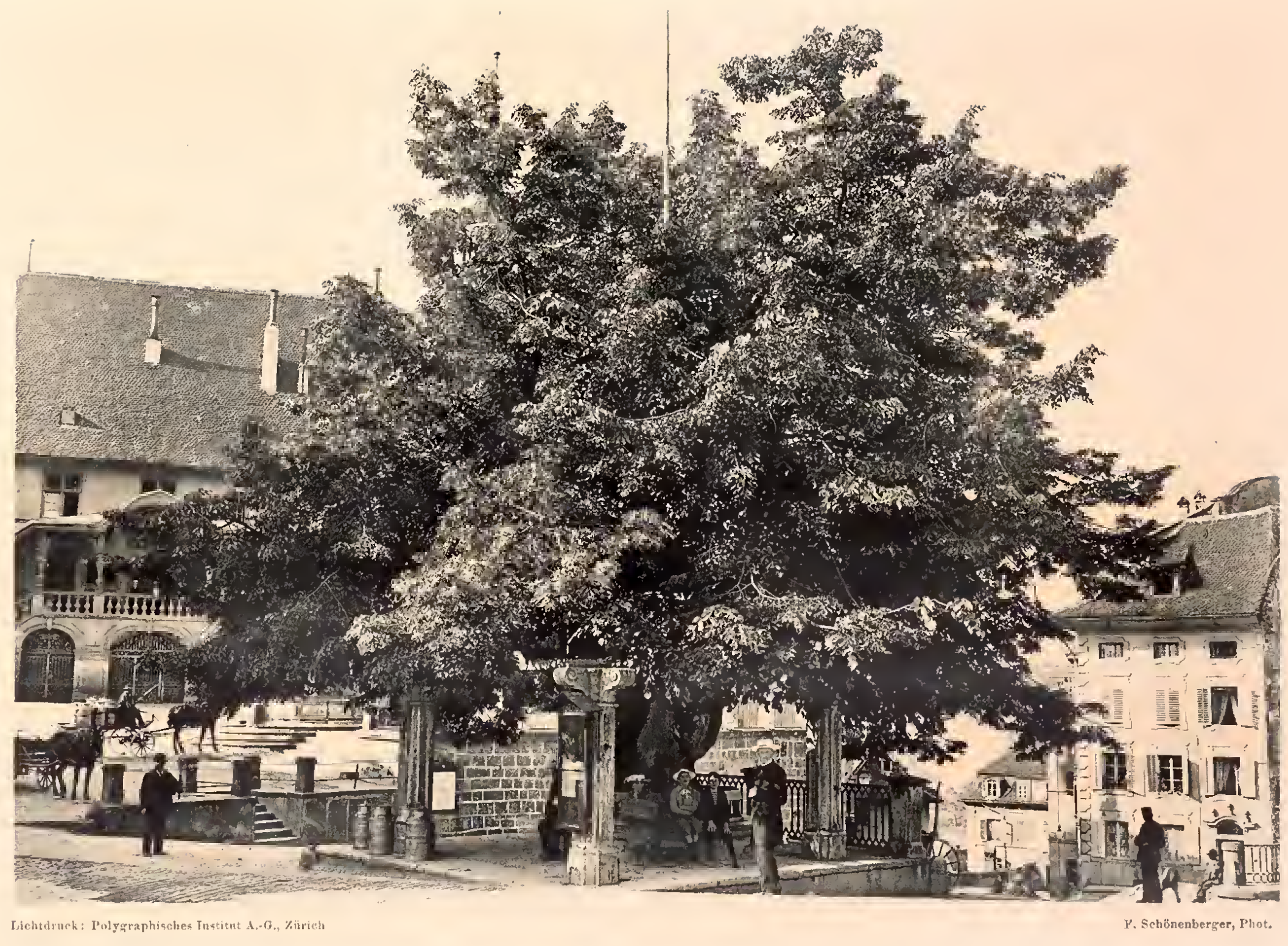


LIBRARY

NEW YORK

BU'TANICAL

OARUEN 


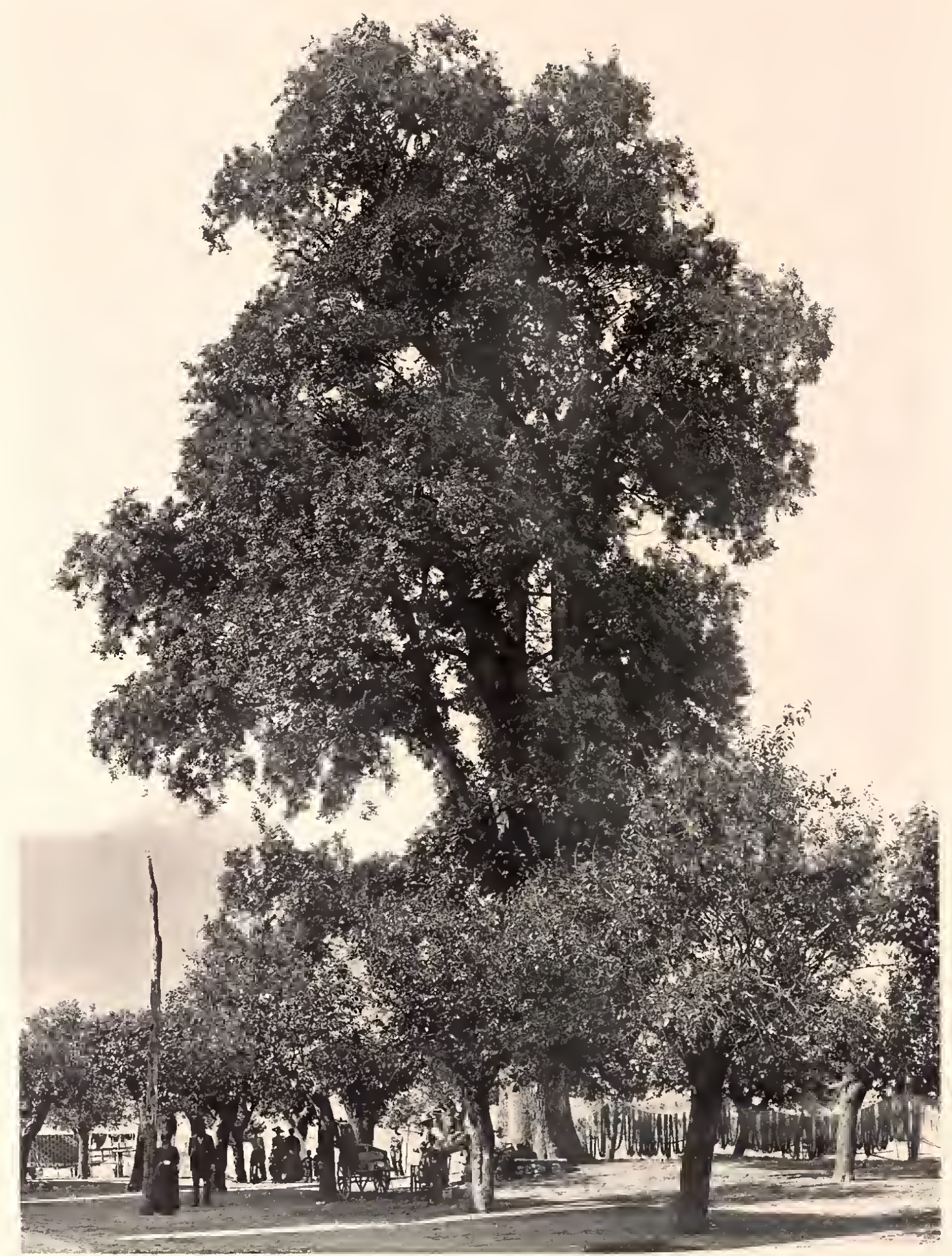

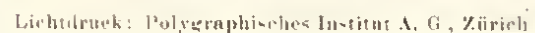


LIBRARY

NEW YORK

BUTANICAL IIARDEN 


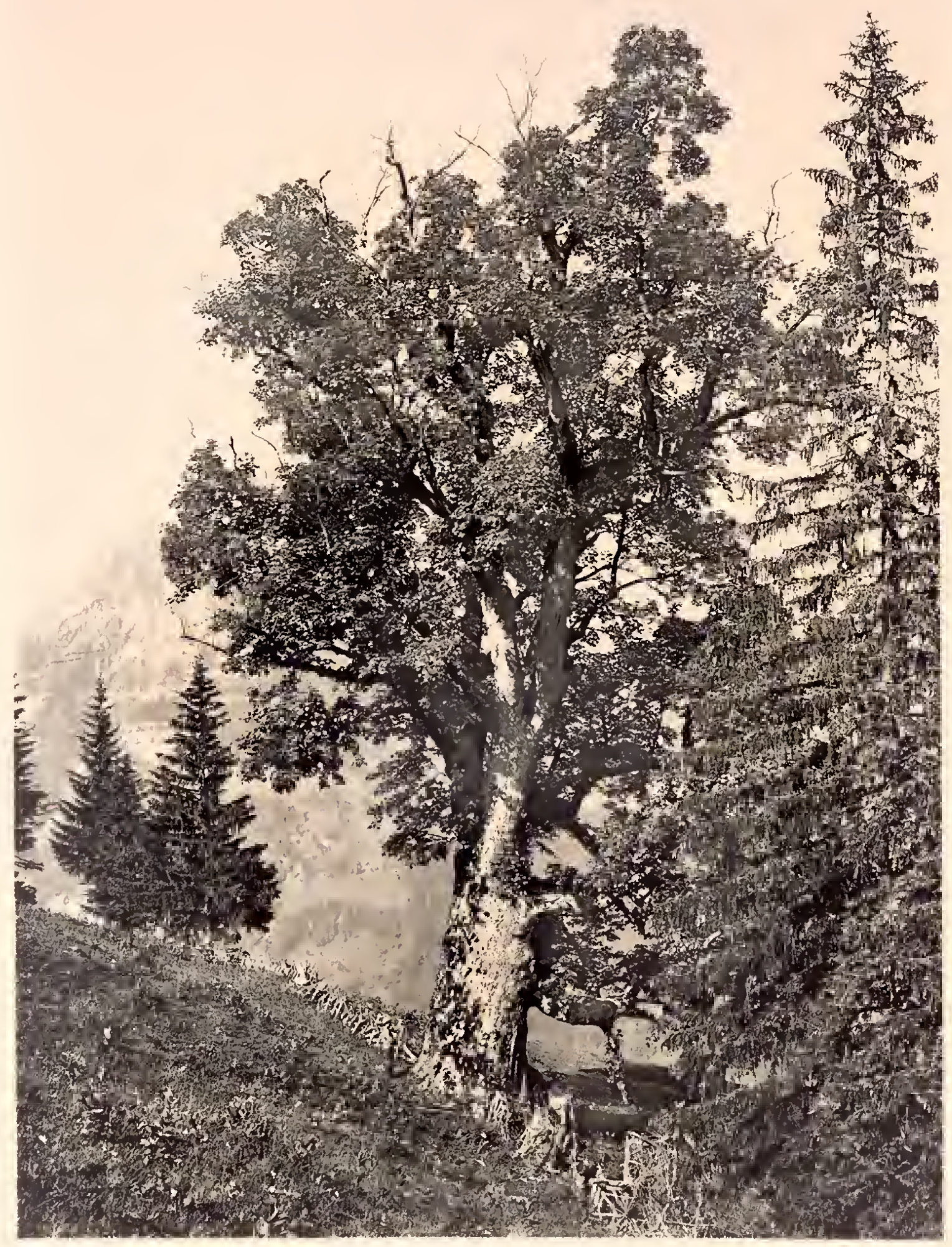

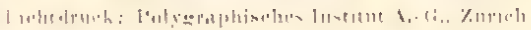




$$
\begin{aligned}
& \text { URDARY } \\
& \text { NEW SURK } \\
& \text { DOTANICAL } \\
& \text { QARDIEN }
\end{aligned}
$$




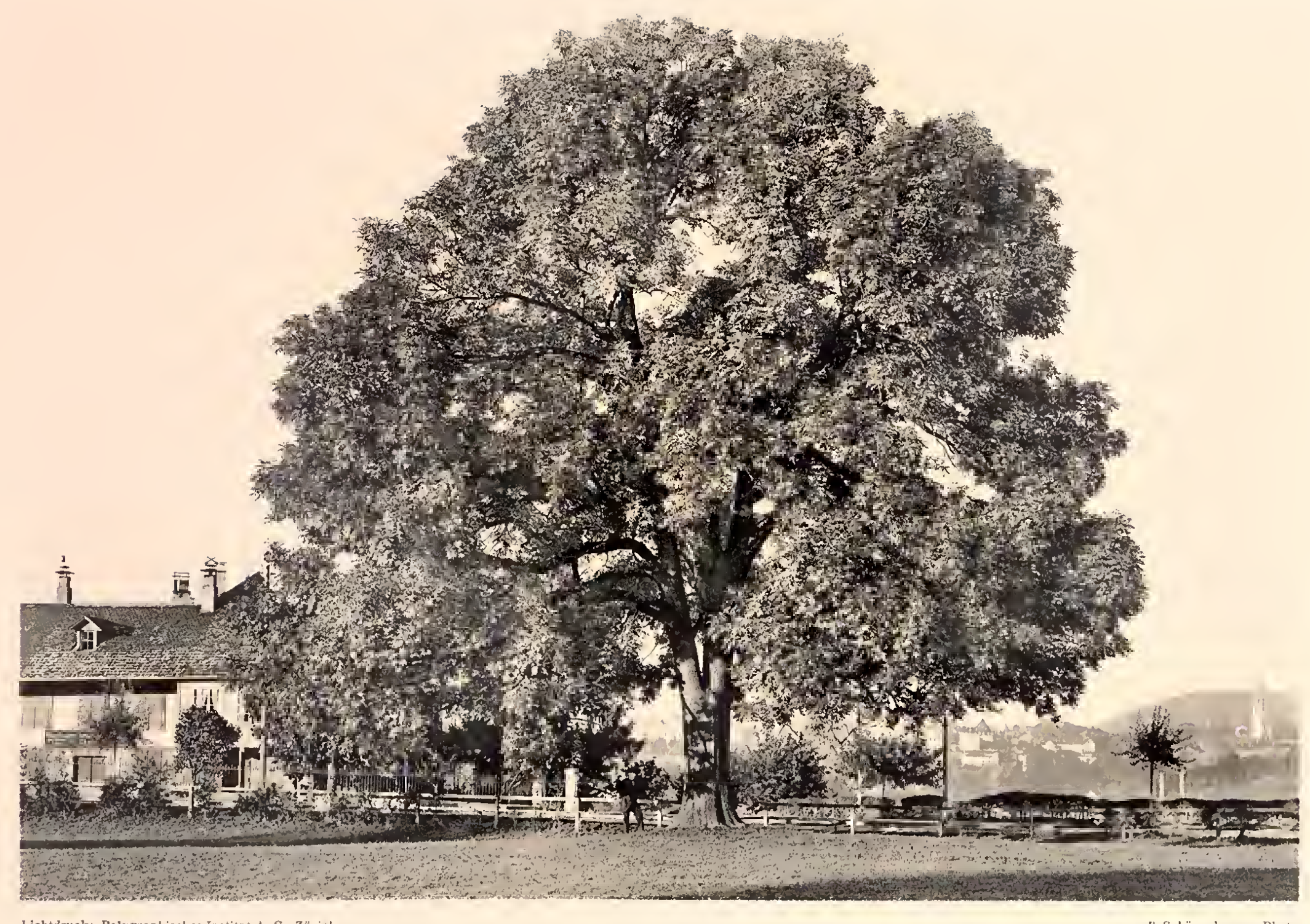

Lichtdruck: Polygraphisches Institut A--G., Zilirich

F. Schönenberger, Phot 
LIBRARY

NEWV YORK

BOTANKCAL

(IARUEN 


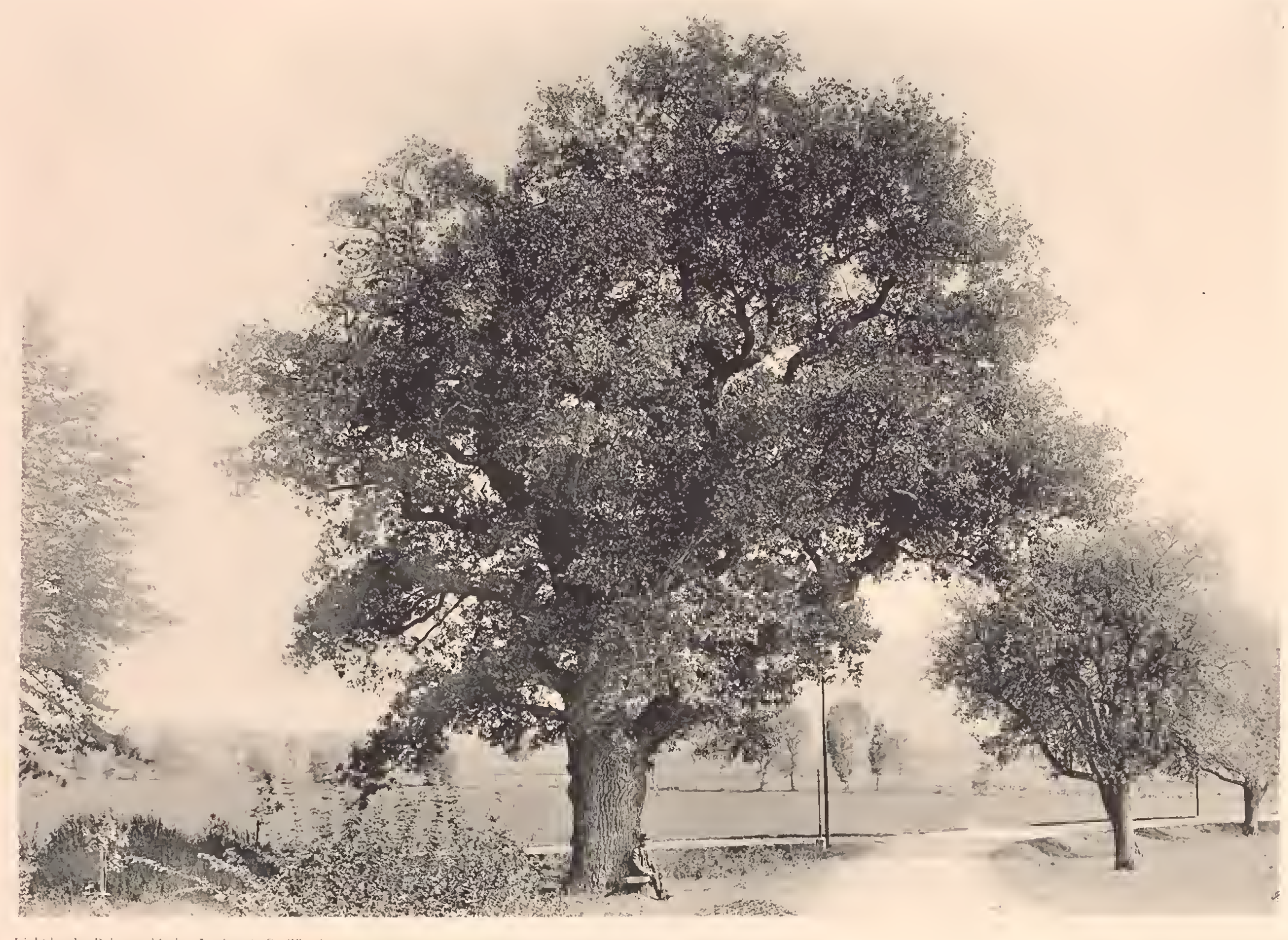


LIBRARY

NEW YORKK

BOT ANIC AL.

GARDEN 


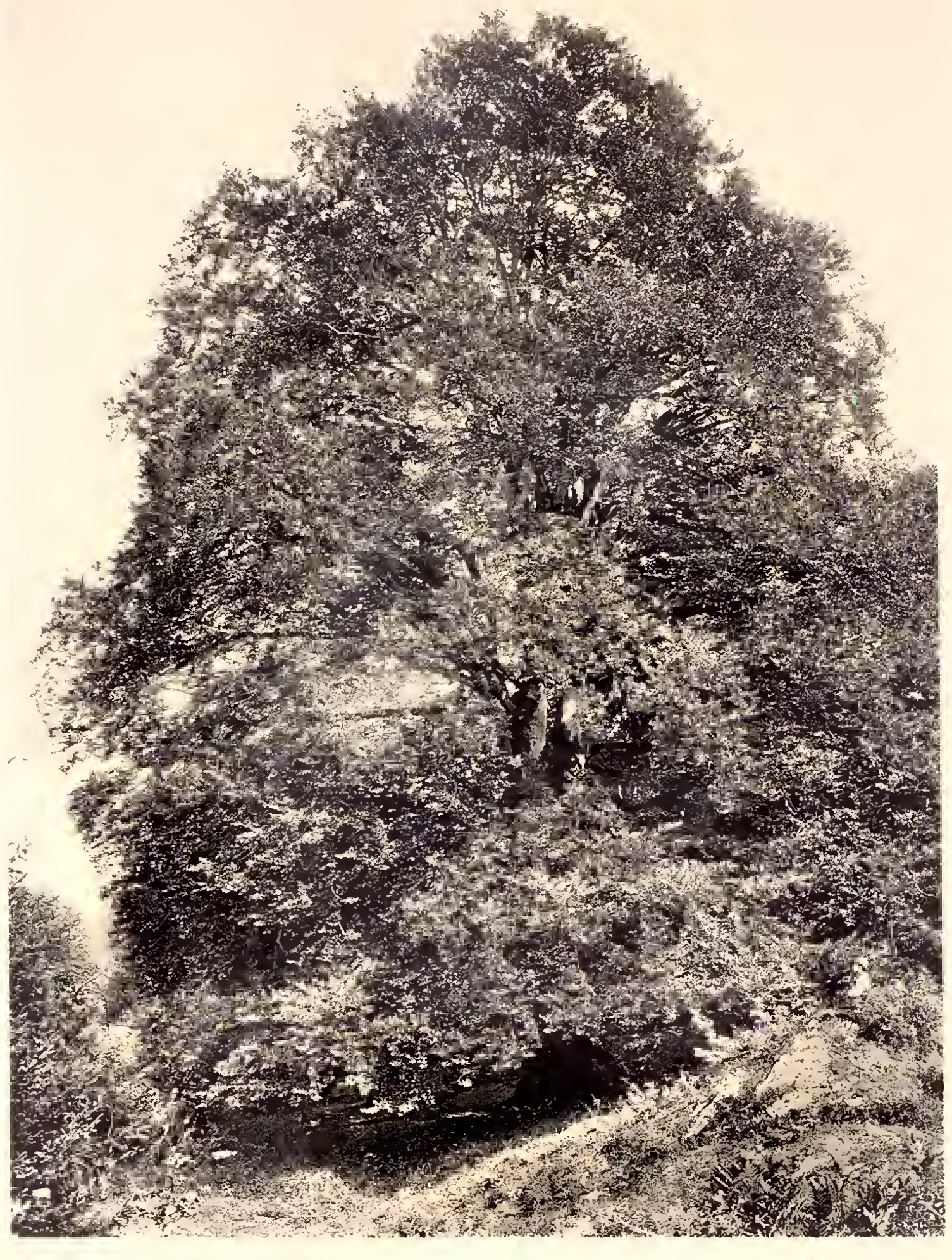

Buche von Flims (Graubünden)

Hêtre de Flims (Grisons) 
LIERARY

NEIV YORK

BOTANICAL

GARDEN 


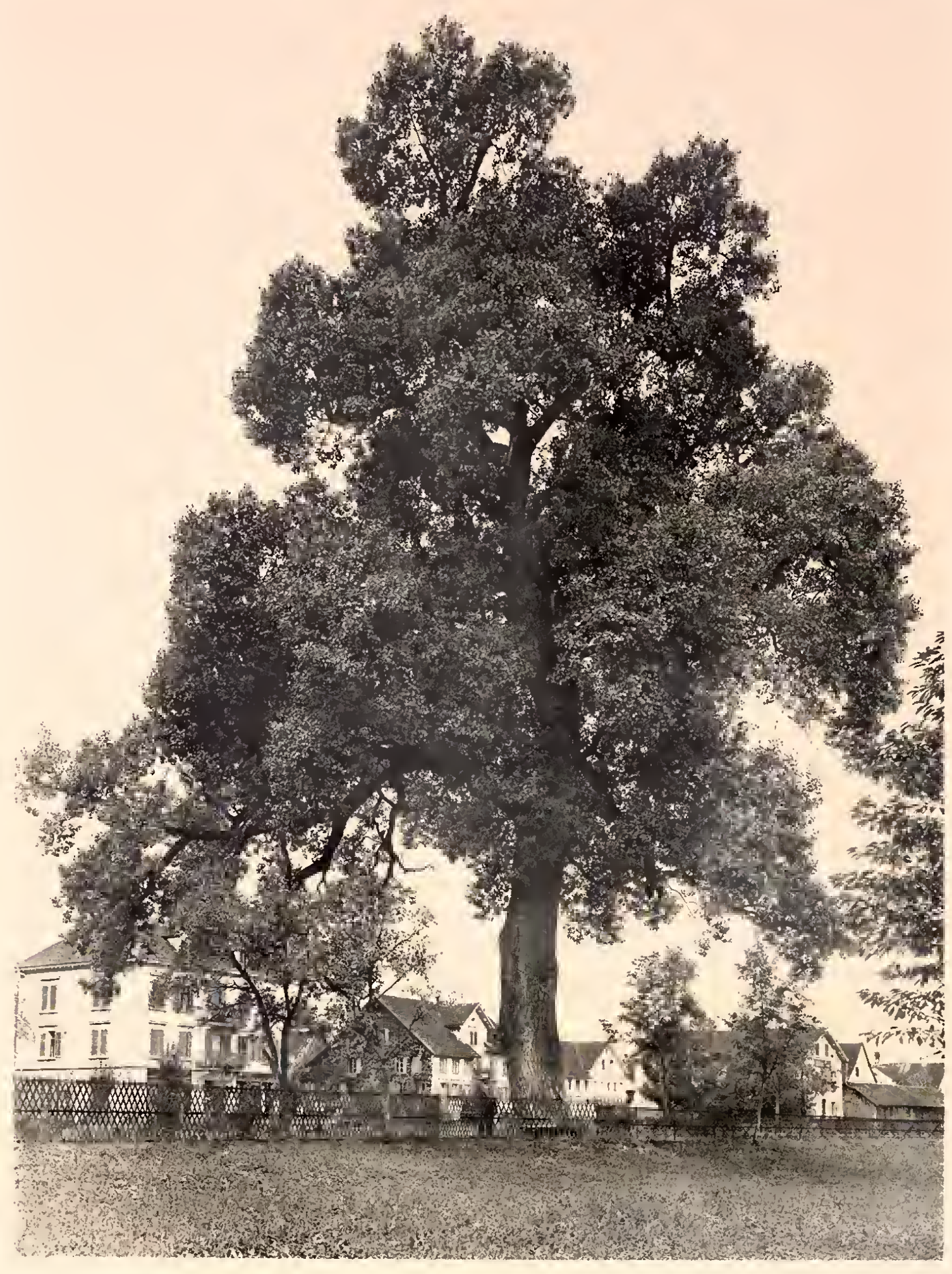


$\pm$ 


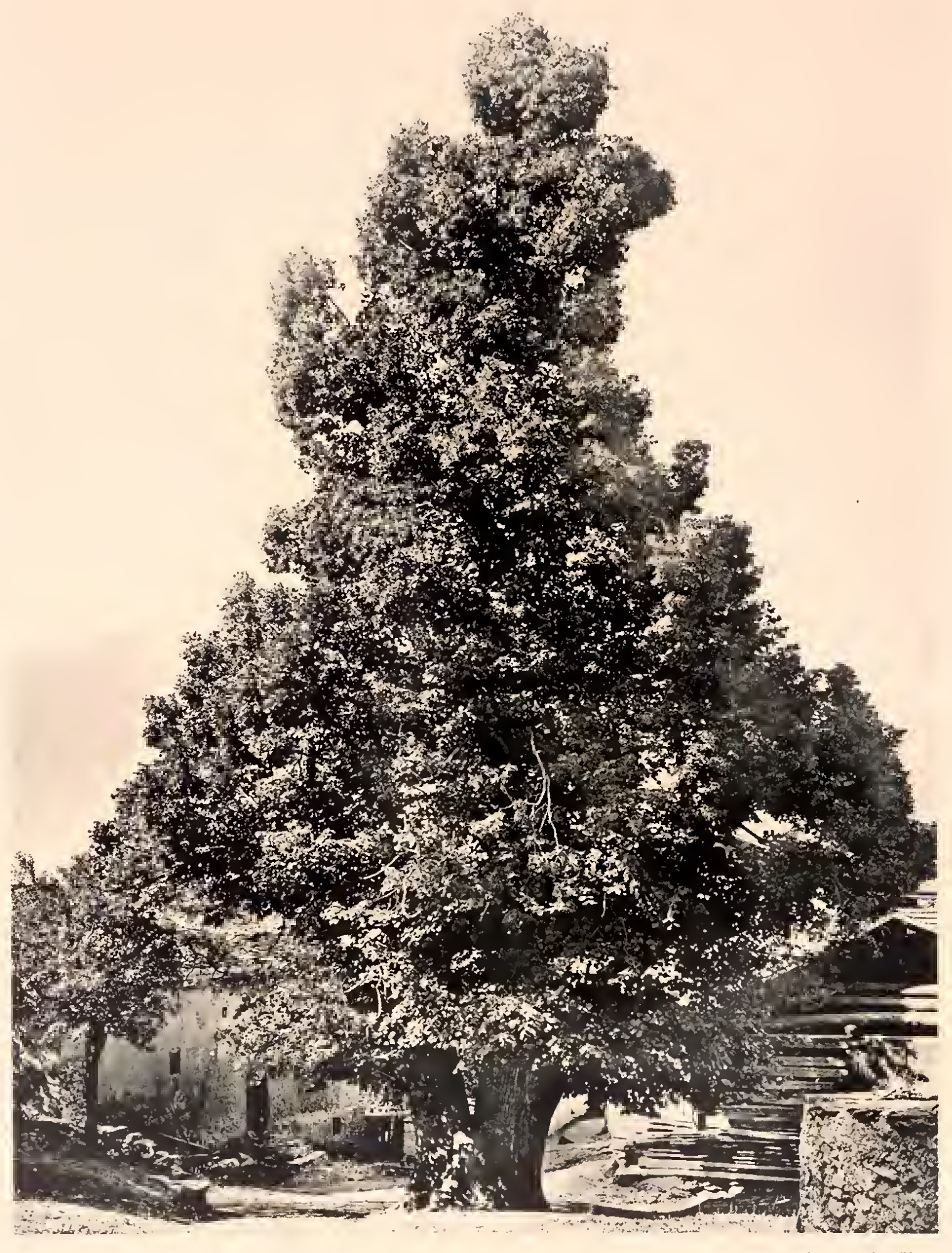

Lichtdruck: Polygraphisches Institut A.G., Zürich

E. Mumenthaler, Phot. 
$\stackrel{ \pm=0}{*}$ 


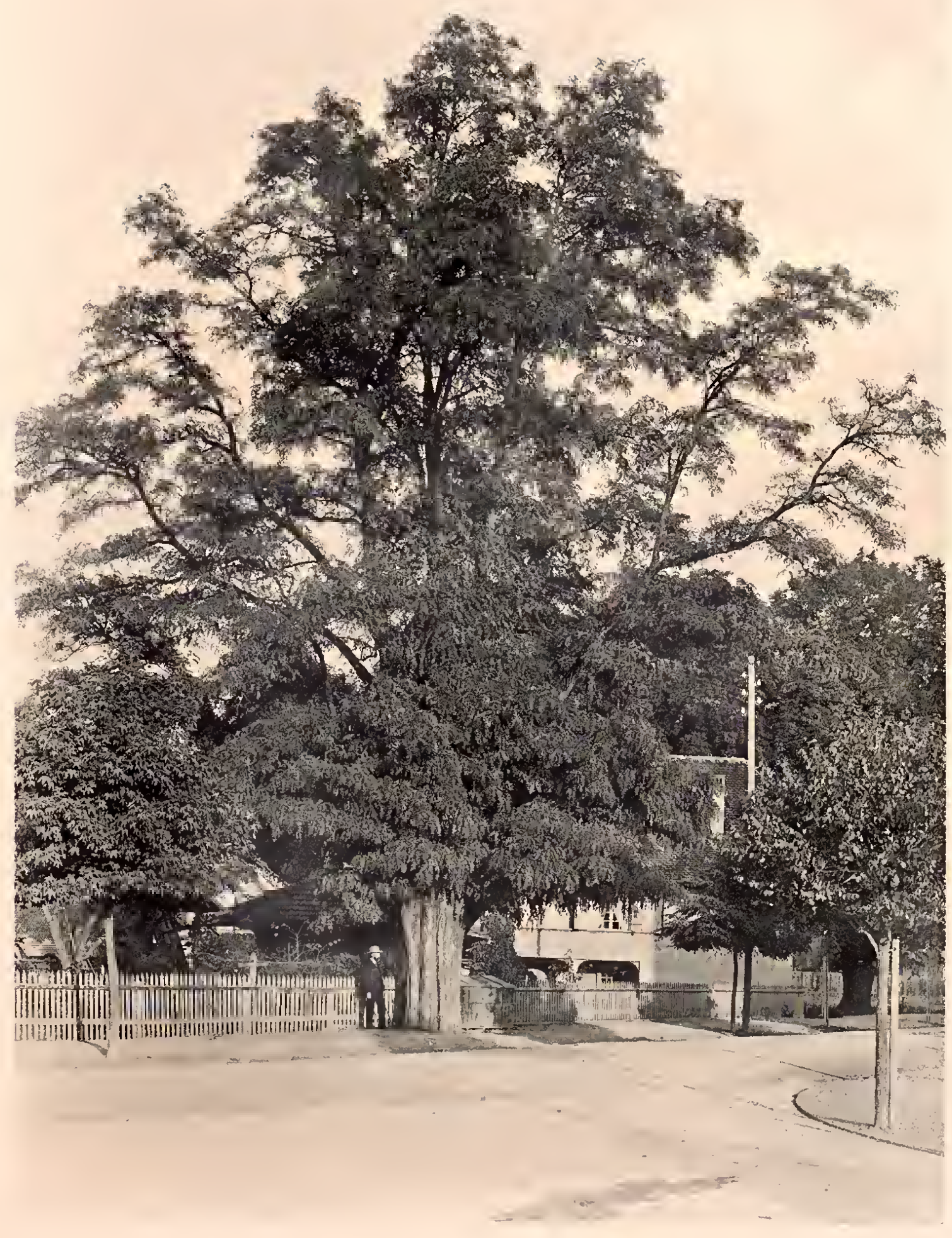


LIBRARY

NEW YURK

BUTANICAL

GARDEN 


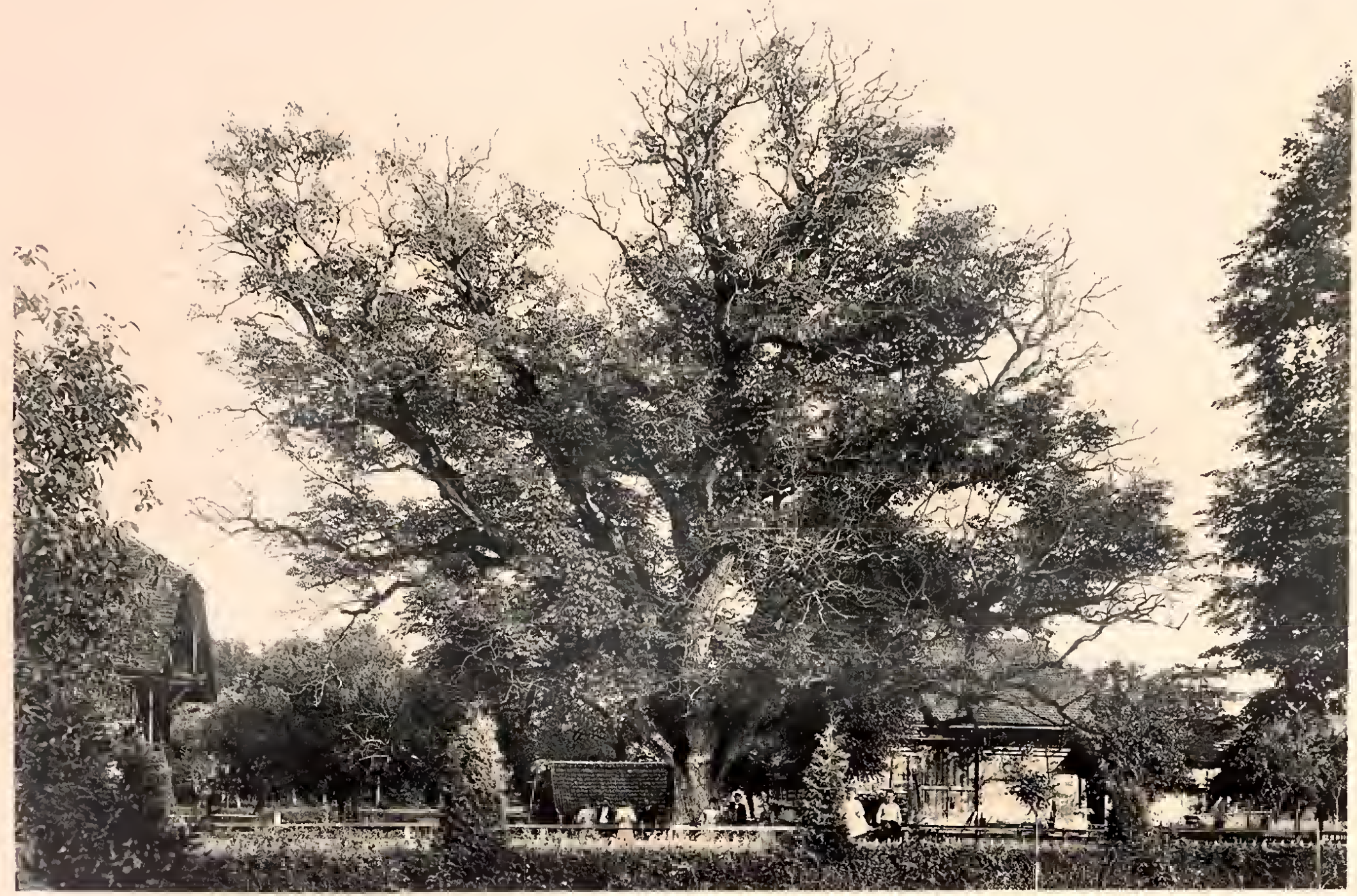

Lichtdruck: Polygraphische, In-ritut A.-G., Ziirich

F. Sclönenbergror, Plot. 
LIIBRARY

NIEW YORK

BOTAMICAL

GARDTEN 


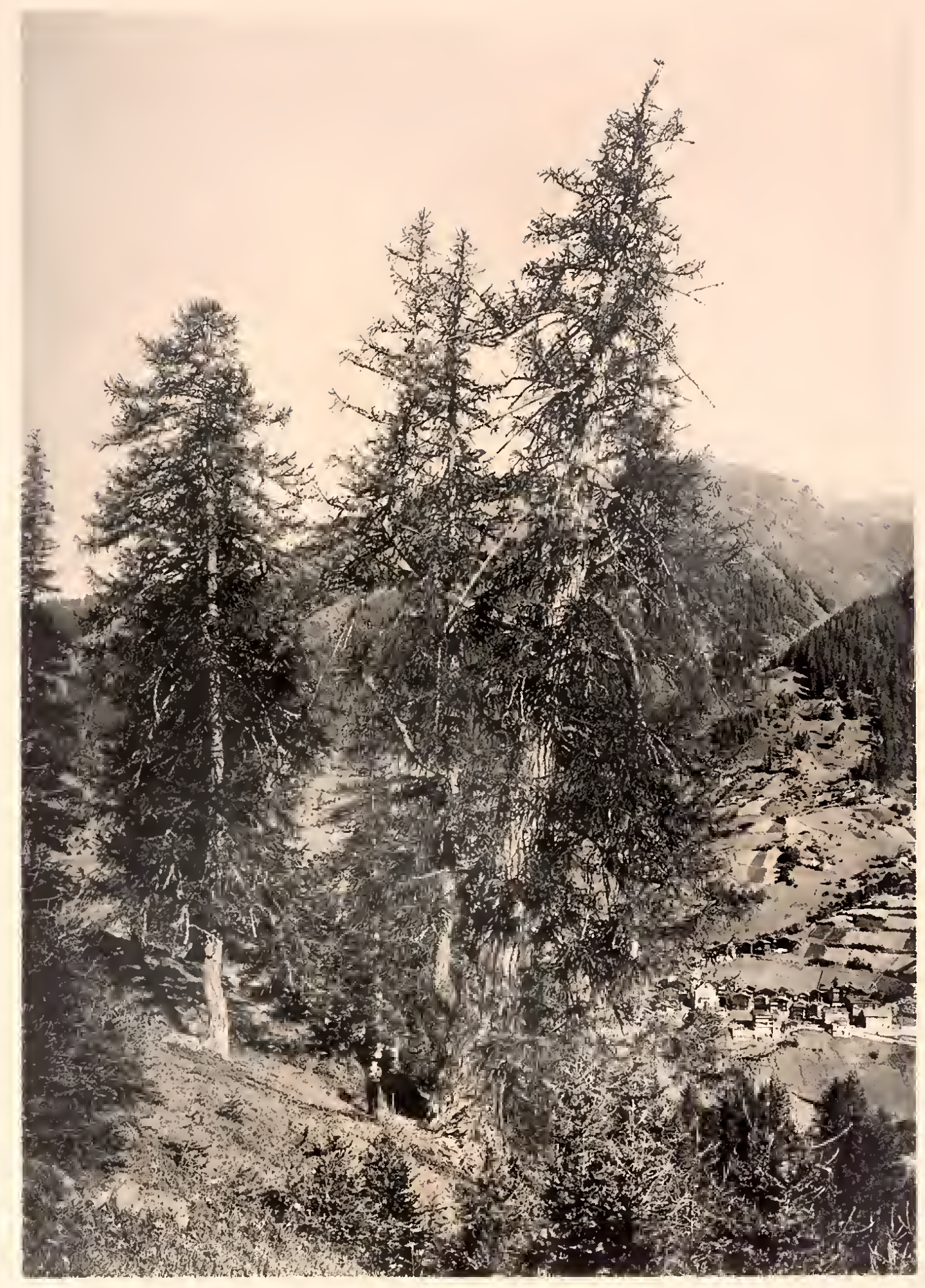


LIBRARY

NEWY YORK

BOTANICAL

OARBON 


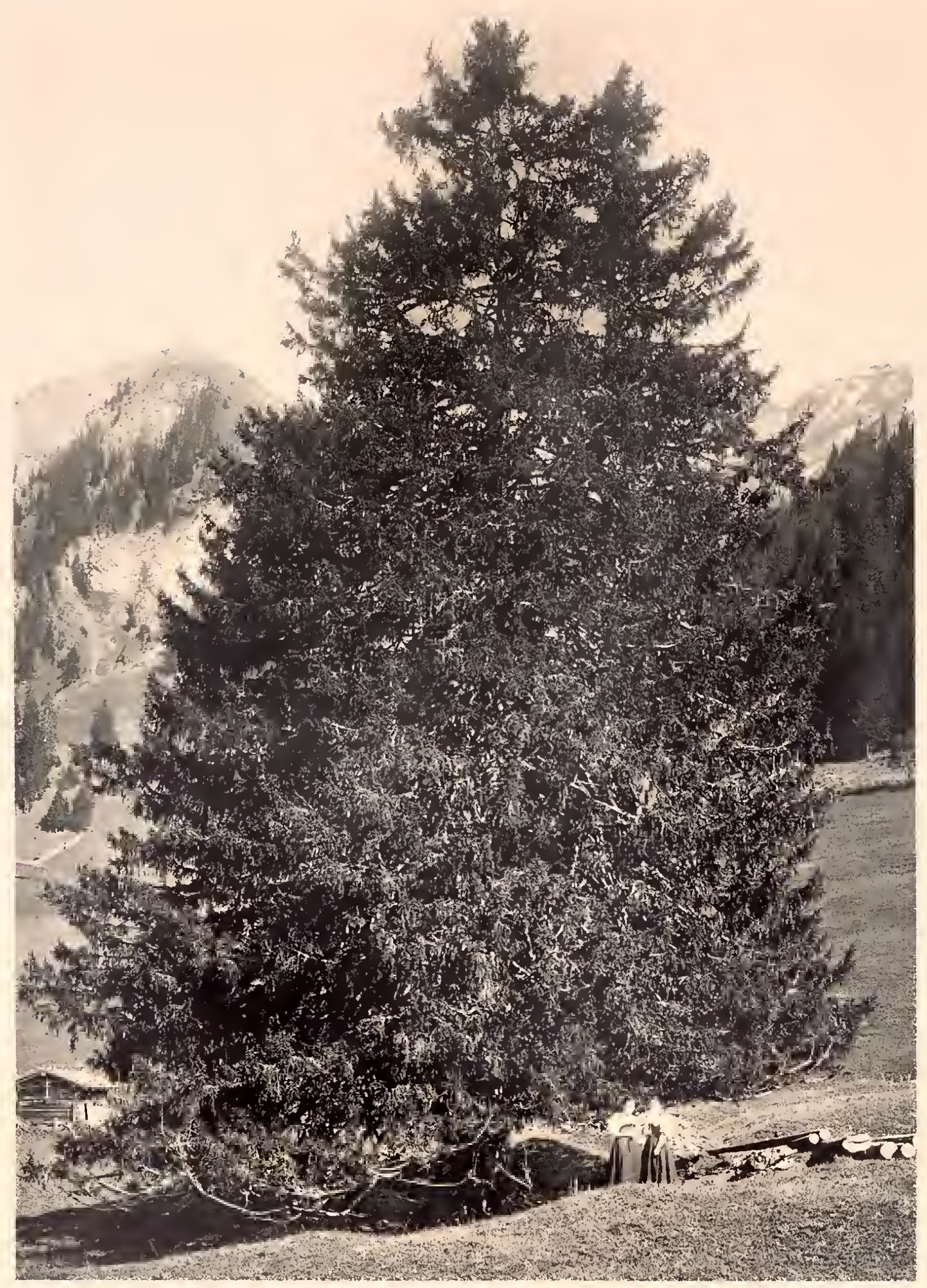

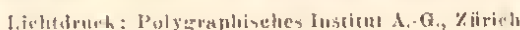

F. Schönenberger, Y̌hot.

Fichte von Adelboden (Kt. Bern)

Epicėa d'Adelboden (Ct. de Berne) 
LIPRAKX

N:SW VORK

BO'TANICAL

C.ARBEN 


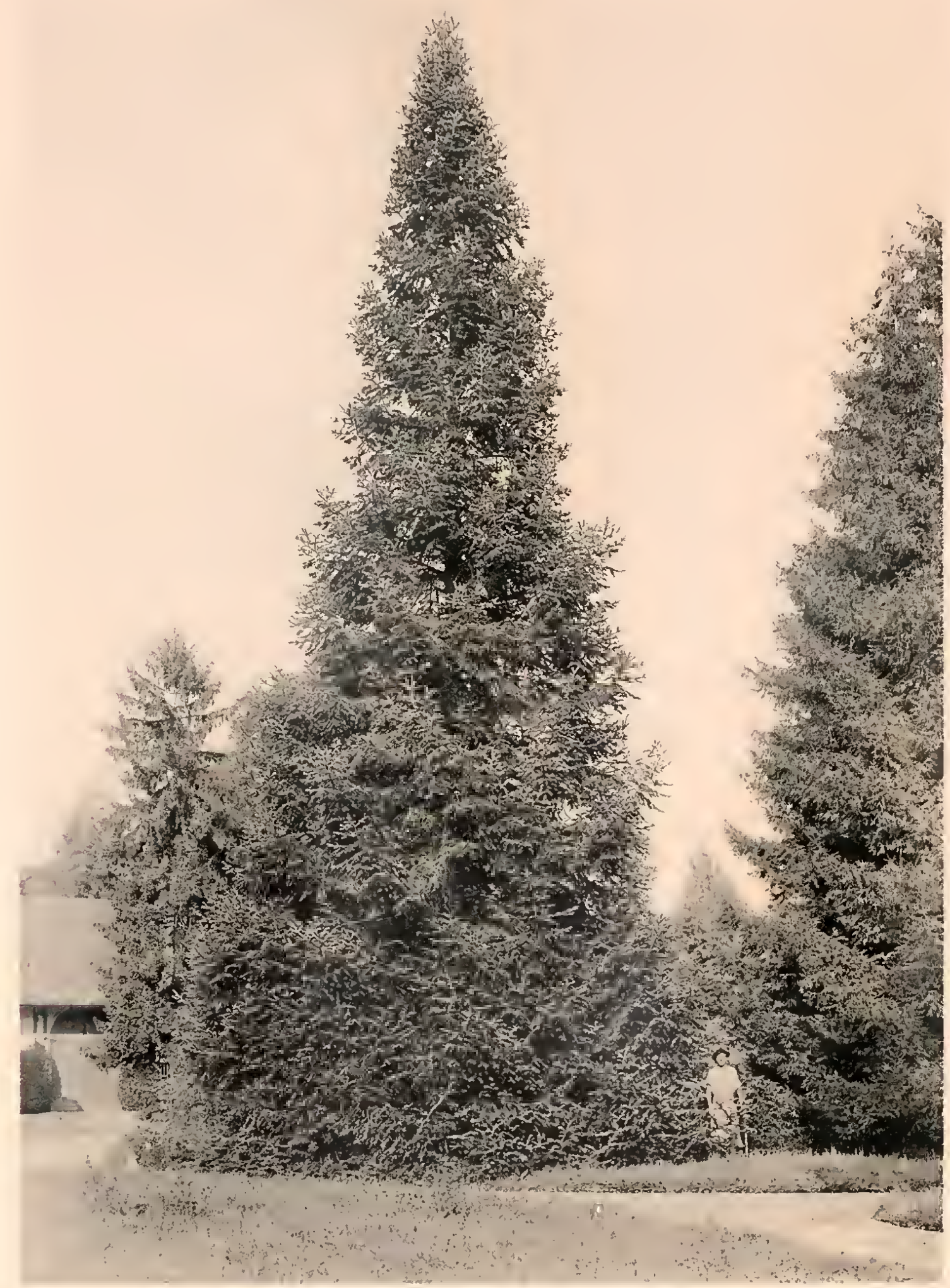

Abies Nordmanniana - Villa Barbey - Genf - Genève 
LIBRA AKY

N:'V VURK

BOTANKAL

(AARZEN 


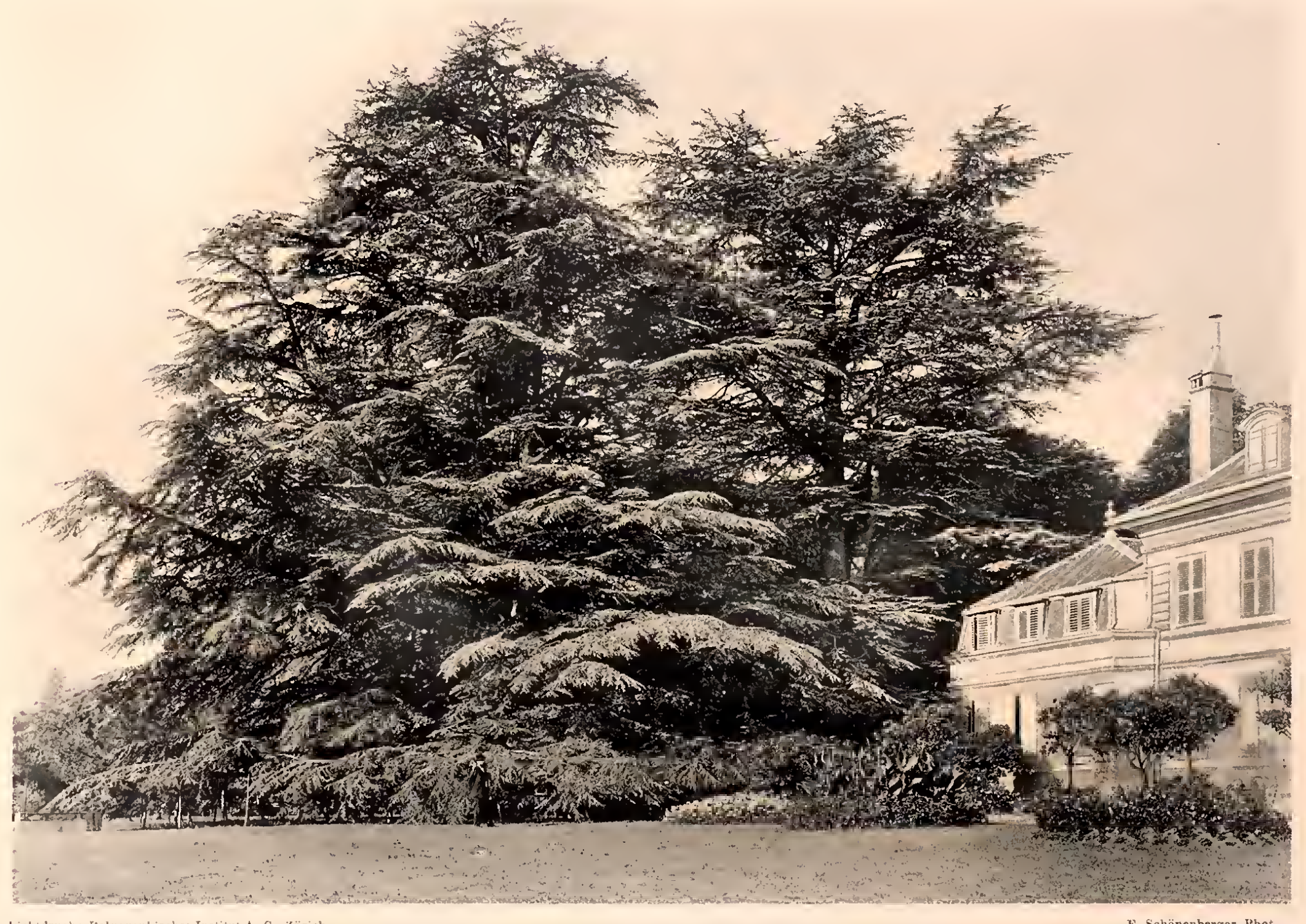

1.jchlt druek: rolygraphisehes Institut A.-G., Kärich

F. Schönenberger, P'hot. 
WIRRARY

I N W

BE:ANUC, L

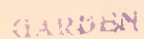




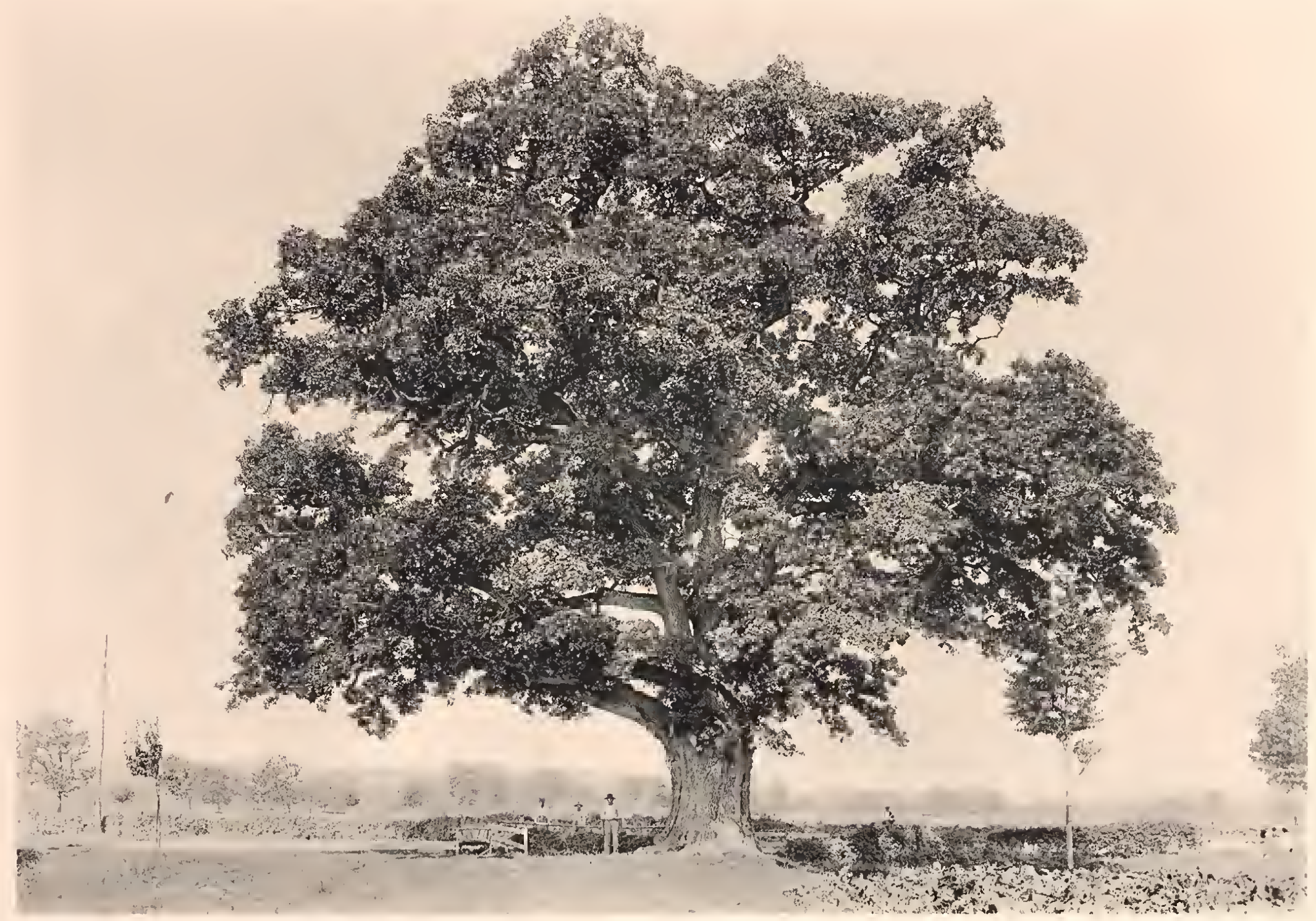




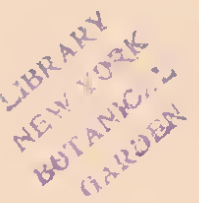




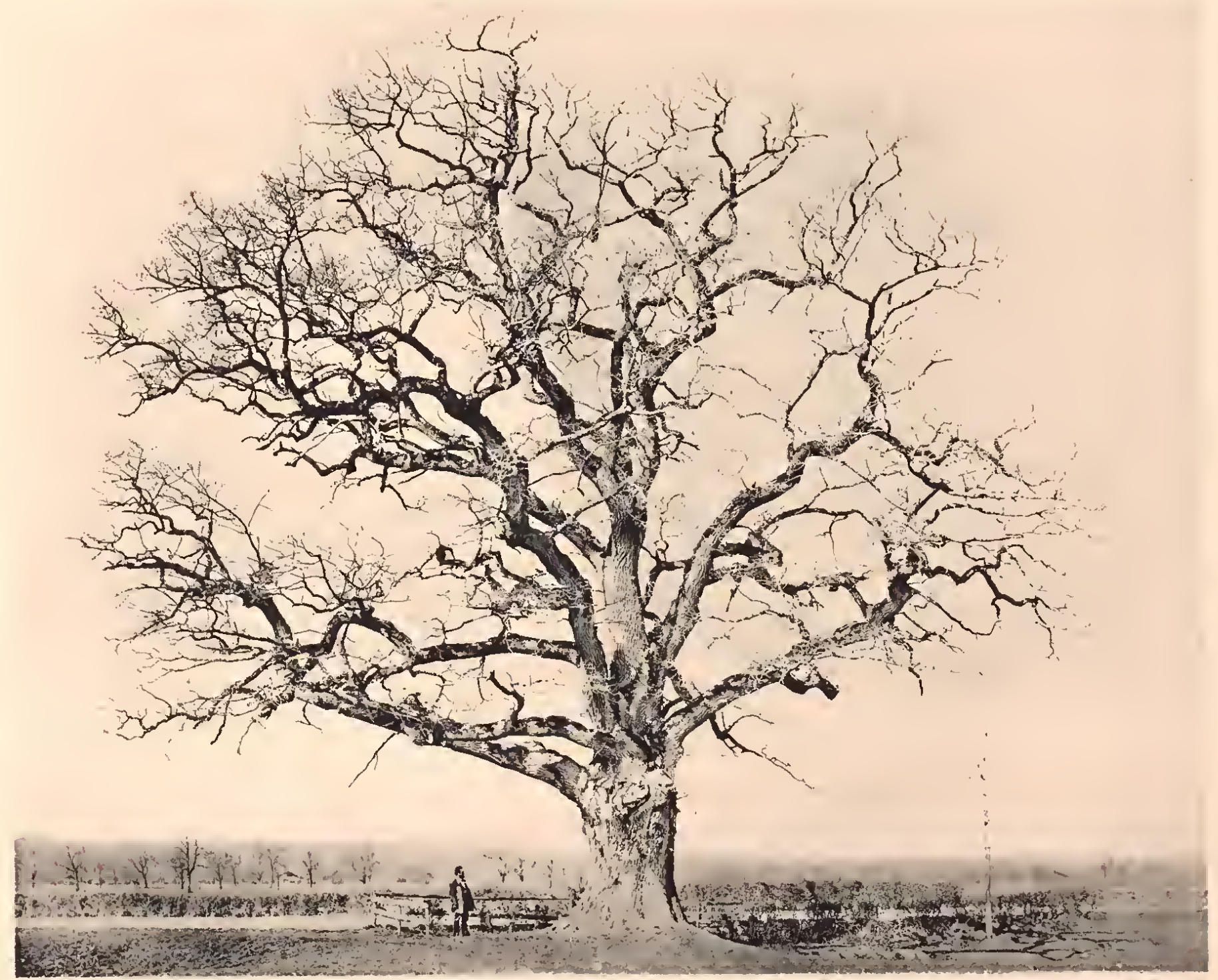

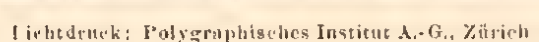

1. Sellünemberger, Phot. 



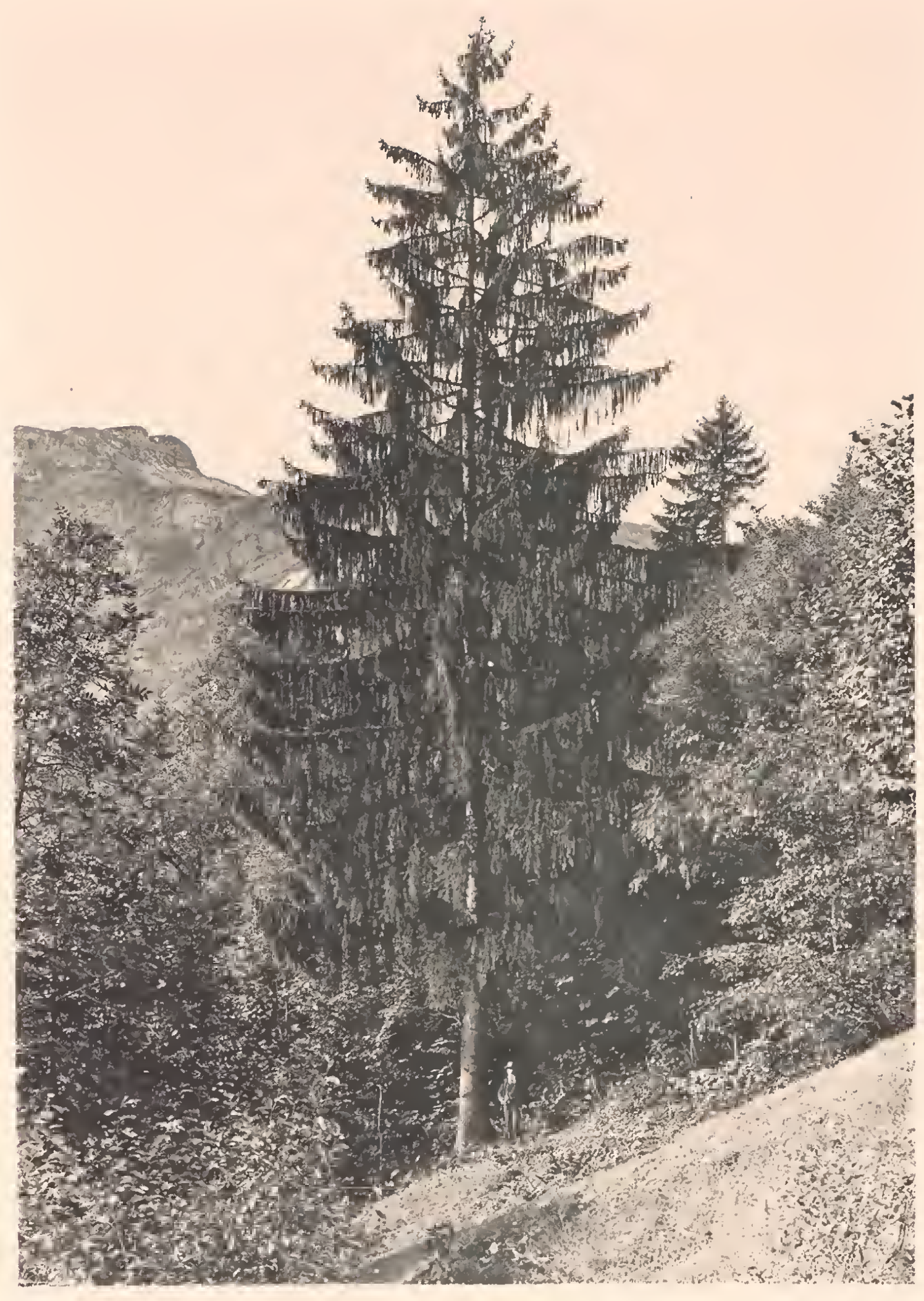

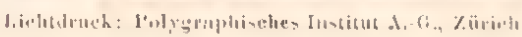

Hängefichte _- Richisau-Klöntal - Epicėa à rameaux pendants 
LIISRARY
NEW YORK
BOTANLAL
GARUEA 


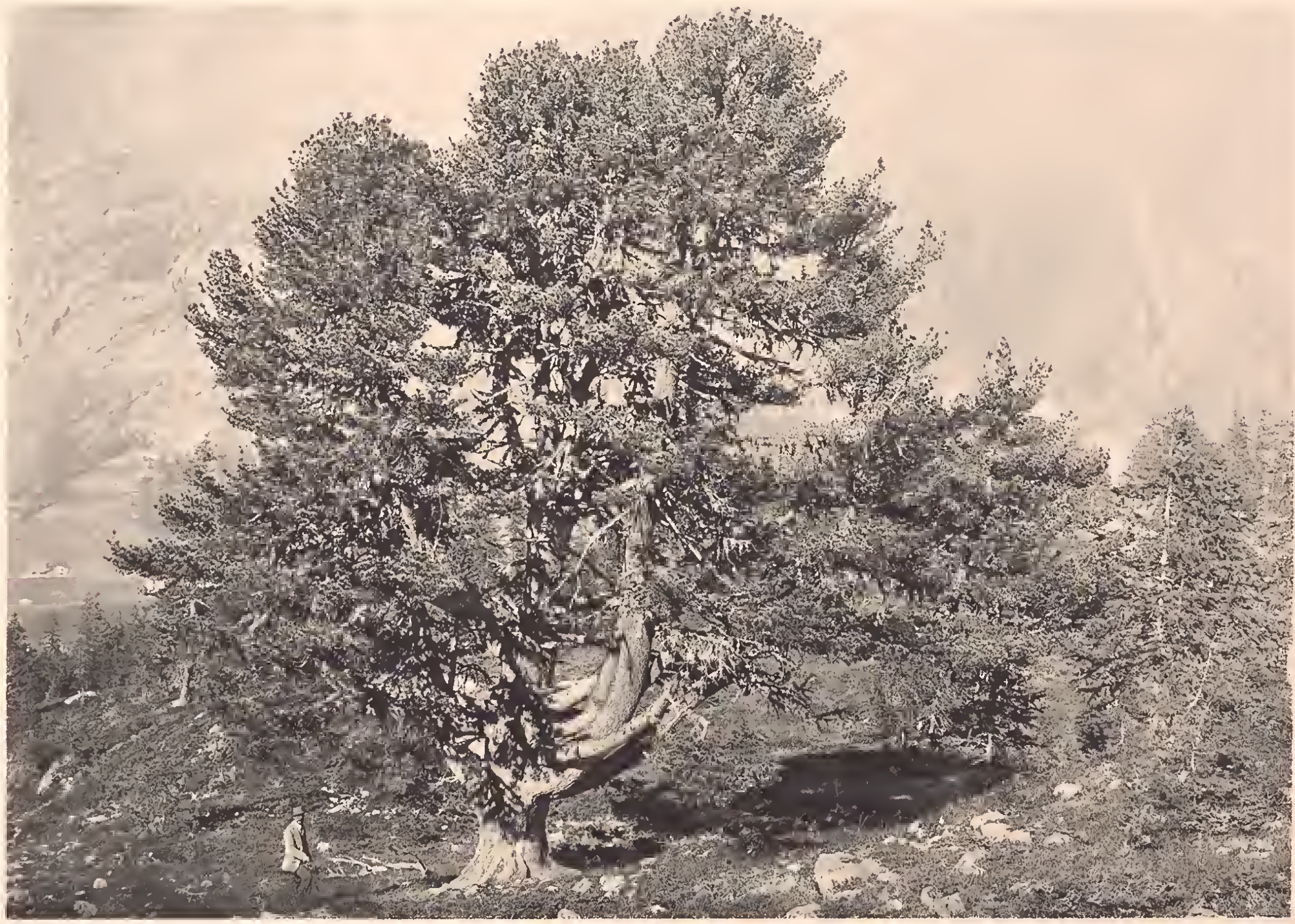

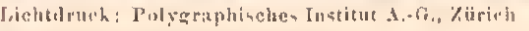

F. Schönenberger, Phot 
IXPSRAKY

Na' ' V URE

BOIANKCAL

CARUEN 


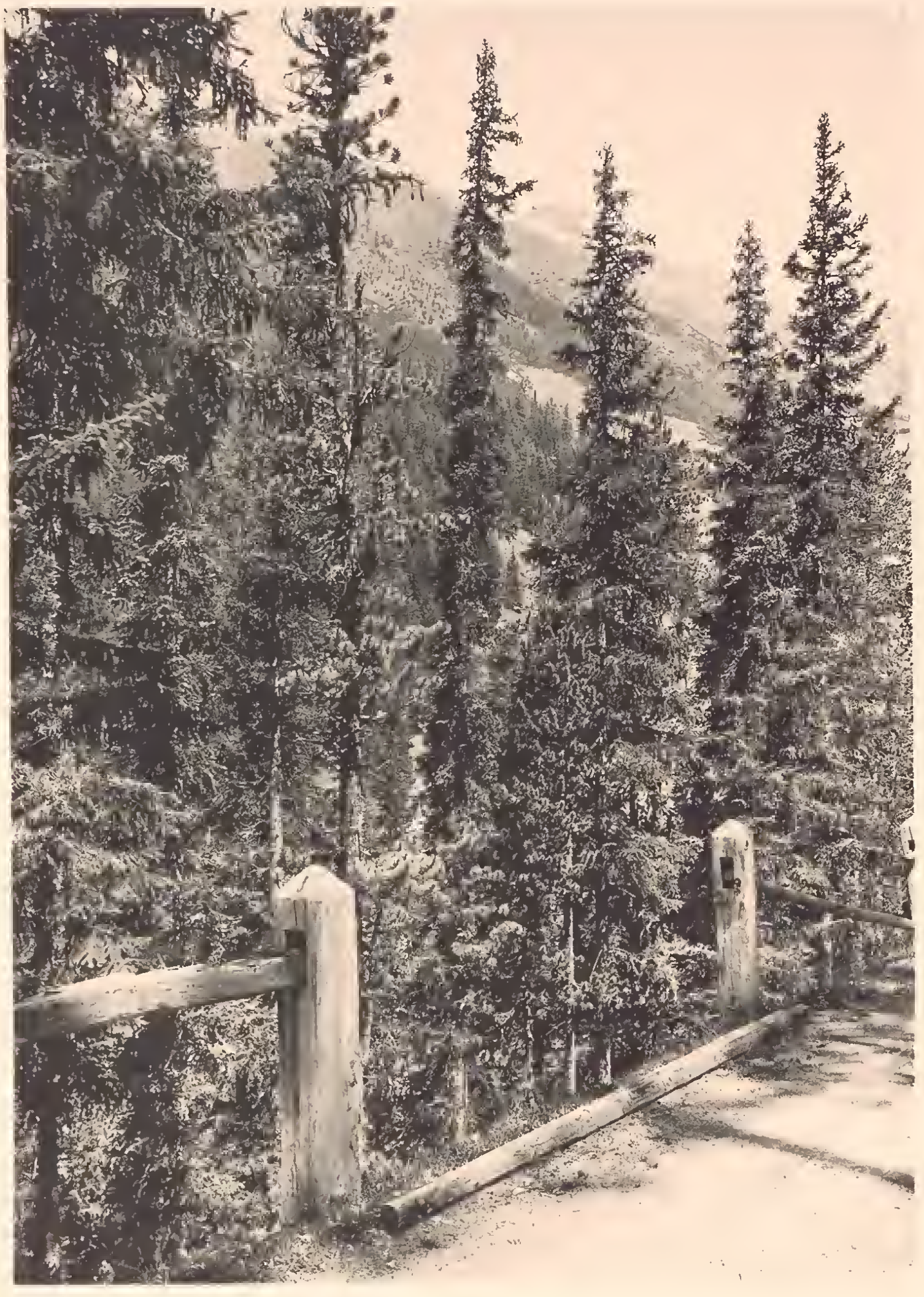

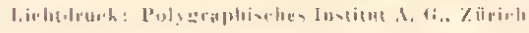

Säulenfichte an dor Ofenstrasse bei Zernez. (Graubünden)

Epicea cylindrique au bord de la route de l'Ofen pres Zernez (Grisons) 


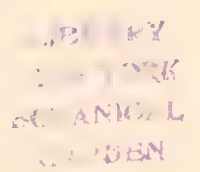




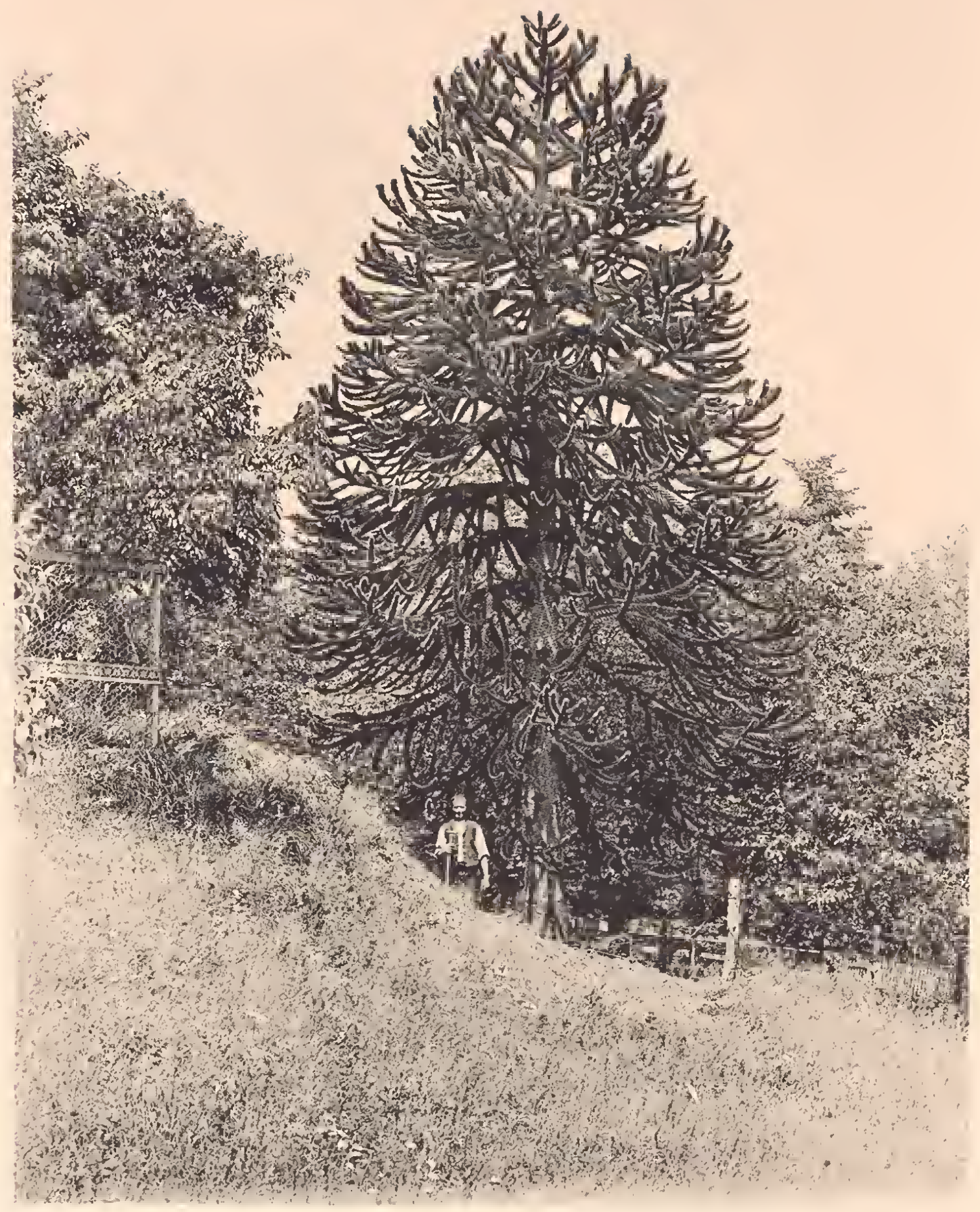

LAchtdruck: Polygraphisches Institut A.G., Zürich 


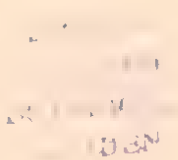

